4 For submission to Geochimica et Cosmochimica Acta

5 Authors:

6 Frank Heberling $^{\mathrm{a}}$, Victor L. Vinograd ${ }^{\mathrm{b}, \mathrm{c}}$, Robert Polly ${ }^{\mathrm{a}}$, Julian D. Gale ${ }^{\mathrm{d}}$, Stephanie Heck ${ }^{\mathrm{a}}$, Jörg Rothe ${ }^{\mathrm{a}}$,

7 Dirk Bosbach ${ }^{b}$, Horst Geckeis $^{\mathrm{a}}$, Björn Winkler ${ }^{\mathrm{c}}$

8 Authors' Affiliations:

9 a: Institute for Nuclear Waste Disposal, Karlsruhe Institute of Technology, PO. Box 3640, 76021 Karlsruhe, 10 Germany

\section{coprecipitation with calcite} \section{Germany}

b: Institute of Energy and Climate Research 6, Forschungszentrum Jülich, Wilhelm Johnen Straße, 52425 Jülich, Germany

c: Institute of Geoscience, Goethe Universität Frankfurt am Main, Altenhöferallee 1, 60438 Frankfurt, Germany

d: Nanochemistry Research Institute, Department of Chemistry, Curtin University, P.O. Box U1987, Perth, WA 6845, Australia

Authors' e-mail addresses:

Frank Heberling: Frank.Heberling@kit.edu

Victor Vinograd: V.Vinograd@fz-juelich.de; V.Vinograd@kristall.uni-frankfurt.de

Robert Polly: Robert.Polly@kit.edu

Julian Gale: J.Gale@curtin.edu.au

Stephanie Heck: Stephanie.Heck@kit.edu

Jörg Rothe: Joerg.Rothe@kit.edu

Dirk Bosbach: d.bosbach@fz-juelich.de

Horst Geckeis: horst.geckeis@kit.edu

Björn Winkler: b.winkler@kristall.uni-frankfurt.de

corresponding author: Frank Heberling, phone: 0049 - (0)721 - 608- 24782 


\section{Abstract}

Selenium is an environmentally relevant trace element, while the radioisotope ${ }^{79} \mathrm{Se}$ is of particular concern in the context of nuclear waste disposal safety. Oxidized selenium species are relatively soluble and show only weak adsorption at common mineral surfaces. However, a possible sorption mechanism for selenium in the geosphere is the structural incorporation of selenium(IV) (selenite, $\mathrm{SeO}_{3}{ }^{2-}$ ) into calcite $\left(\mathrm{CaCO}_{3}\right)$.

In this study we investigate the interactions between selenite and calcite by a series of experimental and computational methods with the aim to quantify selenite incorporation into calcite at standard conditions. We further seek to describe the thermodynamics of selenite-doped calcite, and selenite coprecipitation with calcite.

The structure of the incorporated species is investigated using Se K-edge EXAFS (isotropic and polarization dependent) and results are compared to density functional theory (DFT) calculations. These investigations confirm structural incorporation of selenite into calcite by the substitution of carbonate for selenite, leading to the formation of a $\mathrm{Ca}\left(\mathrm{SeO}_{3}\right)_{x}\left(\mathrm{CO}_{3}\right)_{(1-x)}$ solid solution.

Coprecipitation experiments at low supersaturation indicate a linear increase of the selenite to carbonate ratio in the solid with the increase of the selenite to carbonate ratio in the contact solution, in line with a description of the system by a constant partition coefficient, $D=0.02 \pm 0.01$, or an ideal (or Henry's law) mixing behavior between calcite and a virtual $\mathrm{CaSeO}_{3}$ endmember. The apparent stability and solubility of this endmember are: $\mathrm{G}^{0}\left(\mathrm{CaSeO}_{3_{-} \text {exp }}\right)=-953 \pm 6 \mathrm{~kJ} / \mathrm{mol}$ and $\log _{10}\left(\mathrm{~K}_{\text {sp }}\left(\mathrm{CaSeO}_{3_{-} \text {exp }}\right)\right)=-6.7 \pm$ 1.0. In contrast to this experimental result, DFT and force field calculations indicate that the strain induced in the bulk calcite structure by substitution of carbonate for selenite is so high that the virtual bulk $\mathrm{CaSeO}_{3}$ endmember is predicted to be unstable and highly soluble: $\mathrm{G}^{0}\left(\mathrm{CaSeO}_{3}\right.$ bulk $)=-912 \pm 10$ $\mathrm{kJ} / \mathrm{mol}$ and $\log _{10}\left(\mathrm{~K}_{\mathrm{SP}}\left(\mathrm{CaSeO}_{3}{ }_{\text {bulk }}\right)\right)=0.5 \pm 1.7$.

To overcome this discrepancy we introduce a thermodynamic adsorption/entrapment concept. This concept is based on the idea that the apparent experimental endmember stability reflects a surface state, while the atomistic calculations reflect real bulk thermodynamics. It leads to a number of important consequences, which can be tested both experimentally and theoretically.

DFT calculations confirm that the substitution of carbonate for selenite is energetically more favorable at the surface than inside the bulk. Selenite adsorption at calcite equilibrium is equivalent to the formation of a surface monolayer solid solution and occurs with the same partition coefficient as coprecipitation from supersaturated solution. Calcite growth inhibition in the presence of selenite can be related to the fact that the aqueous solution is supersaturated with respect to calcite, but undersaturated with respect to the bulk solid solution of $\mathrm{CaSeO}_{3}$ in calcite.

Overall, the calcite- $\mathrm{CaSeO}_{3}$ solid solution can only grow continuously if the solution is supersaturated with respect to the bulk solid solution. Under these conditions selenite coprecipitates with calcite at a partition coefficient of $D=0.02 \pm 0.01$. If the solution is undersaturated with respect to the bulk solid solution, only surface ion-exchange occurs. Elevated selenite concentrations in bulk calcite therefore reflect non-equilibrium conditions. 


\section{Introduction}

As for many elements, selenium is on the one hand an essential nutrient for animals and humans, while on the other hand above certain concentration limits it is toxic (Fernández-Martínez and Charlet, 2009). The critical issue in the case of selenium is that the acceptable range of selenium intake is relatively narrow (e.g. for humans the lower and upper bounds are $40 \mu \mathrm{g} /$ day versus $400 \mu \mathrm{g} /$ day, respectively). The bioavailability of selenium in natural systems depends to a large degree on its chemical speciation. Depending on the geochemical milieu ( $\mathrm{pH}$-Eh conditions) of natural systems selenium may be present in various oxidation states: $-I I,(-I), 0,+I V$, and $+\mathrm{VI}$. Solid phases formed by reduced and elemental selenium are less soluble compared to phases formed by the oxidized species selenium (IV) and (VI) (Olin et al., 2005). Oxidized selenium forms the oxyanions selenite, $\mathrm{Se}(\mathrm{IV}) \mathrm{O}_{3}{ }^{2-}$, and selenate, $\mathrm{Se}(\mathrm{VI}) \mathrm{O}_{4}{ }^{2-}$, in aqueous solution. Compared to the reduced species, the oxidized species need to be considered more mobile in subsurface environments (Masscheleyn et al., 1990) and show a higher chemical toxicity (FernándezMartínez and Charlet, 2009).

In the context of nuclear waste disposal, the radioisotope ${ }^{79} \mathrm{Se}$ is of special concern due to its long halflife $\left(3.27 \cdot 10^{5}\right.$ years (Jorg et al., 2010)) and expected high mobility. It is created in nuclear reactors by the fission of ${ }^{235} \mathrm{U}$. The Belgian nuclear waste management organization ONDRAF/NIRAS for example, has concluded that ${ }^{79} \mathrm{Se}$ is a potentially critical radionuclide that might, within a relevant timeframe $\left(10^{4}-\right.$ $10^{5}$ years), diffuse through the geological barrier (Boom Clay) and increase the radiotoxicity in adjacent aquifers (Ondraf/Niras, 2001).

Sorption reactions with surrounding mineral phases may have an essential impact on the mobility and bioavailability of the oxidized selenium species in soils and sediments. Numerous sorption mechanisms have been observed and characterized on a molecular scale within the past few decades. Besides the pure surface reactions (outer-sphere and inner-sphere adsorption, or ion exchange) structural incorporation into mineral phases as a consequence of coprecipitation or recrystallization (dissolution/reprecipitation) reactions has significant potential to immobilize toxic trace elements, such as selenium, in soils and aquifers.

Calcite is the most common polymorph of calcium carbonate and the thermodynamically most stable at standard conditions (room temperature and atmospheric pressure). It is abundant in many environmental settings and plays a key role in controlling the geochemical milieu ( $\mathrm{pH}$, alkalinity) of soils and ground water. In the surroundings of potential nuclear waste disposal sites calcite may be present, for example, as a mineral constituent in clay formations (up to $20 \%$ in some cases), as a fracture filling material in granitic rocks, or as a corrosion product of concrete based materials in the technical barrier. Due to the high reactivity of its surface and its tendency to tolerate considerable variation in its chemical composition, calcite has often been considered as a mineral phase with considerable potential for the sequestration of toxic metals. Many studies have investigated the adsorption and incorporation of environmentally relevant elements onto/into calcite (Blanchard and Baer, 1992; Carroll et al., 1992; Elzinga et al., 2006; Heberling et al., 2008; Reeder et al., 2000; Rouff et al., 2005; Tesoriero and Pankow, 1996; Zhong and Mucci, 1995). Wang and Liu (2005) were able to show that calcite has a significant impact on the mobility of selenium in soils. 
Cowan et al. (1990) published a systematic investigation of selenite adsorption on calcite. They found decreasing adsorption with increasing $\mathrm{pH}$ in the range from 7 to 9 . Competing anionic ligands $\left(\mathrm{SO}_{4}{ }^{2-}\right.$, $\mathrm{PO}_{4}{ }^{3-}$ ) cause decreased selenite adsorption, while $\mathrm{Mg}^{2+}$ has no significant influence on selenite adsorption. They proposed a thermodynamic model for selenite adsorption on calcite based on surface ion-exchange reactions. The surface ion-exchange mechanism for selenite sorption at calcite has been confirmed by X-ray standing wave measurements by Cheng et al. (1997). They found after 24 hours of adsorption, starting from undersaturated conditions, selenite incorporated into the surface monolayer of a calcite single crystal.

Recent studies have shown that upon coprecipitation with calcite from highly supersaturated solutions $\left(0.5 \mathrm{~mol} / \mathrm{L} \mathrm{Ca}^{2+}\right.$ and $\mathrm{CO}_{3}{ }^{2-}$ ) (Aurelio et al., 2010) and at elevated temperatures and pressures $\left(30-90{ }^{\circ} \mathrm{C}\right.$, 25-90 bar) (Montes-Hernandez et al., 2011) selenite can be incorporated into calcite. EXAFS Se K-edge spectroscopy and neutron scattering experiments were used to characterize the structural environment of selenite in calcite and the influence of selenite incorporation on the calcite lattice. A density functional theory (DFT) based theoretical investigation of the structural environment of selenite in calcite was also presented. Based on these results the authors propose that selenite substitutes for carbonate in the calcite structure (Aurelio et al., 2010). Most recently Renard et al. (2013) published an Atomic Force Microscopy study, where they investigated the influence of selenium on calcite growth. Selenite is shown to influence the morphology of growth hillocks as well as the growth rates.

In the study presented here the structural incorporation of selenite into calcite is further investigated. Coprecipitation experiments at room temperature and surface controlled growth conditions are used to prepare selenite-doped calcite samples. The structural environment of selenite in calcite is characterized using on the one hand Se K-edge EXAFS spectroscopy measured on selenite-doped calcite powder, and on the other hand polarization dependent Se K-edge EXAFS measured on a selenite-doped calcite single crystal. Selenite incorporation into calcite is quantified at various selenite concentrations $\left(10^{-13} \mathrm{M}\right.$ to $10^{-4}$ $\mathrm{M})$ at surface controlled growth conditions for a range of calcite supersaturations ( $\mathrm{SI}^{1}$ (calcite): $0.14-0.9$ ). The experimental results are compared to DFT-based theoretical investigations of selenite incorporation into bulk calcite and into the calcite (104) surface. The statistical-thermodynamic properties are modeled here with a modified version of the recently introduced Single Defect Method, SDM (Sluiter and Kawazoe, 2002; Vinograd et al., 2013). The present version of the SDM is specially adapted for the thermodynamic description of a non-isostructural solid solution.

Besides the structural characterization of the selenite incorporation species in calcite, the main focus of this study is quantification and modeling of selenite incorporation into calcite at equilibrium and steady state experimental conditions.

\footnotetext{
${ }^{1}$ Saturation index, e.g. SI (calcite $)=\log _{10}\left(a\left(\mathrm{Ca}^{2+}\right) \cdot \mathrm{a}\left(\mathrm{CO}_{3}{ }^{2-}\right) / \mathrm{K}\right.$ sp $($ calcite $\left.)\right)$.
} 

into calcite

143 To describe the affinity of a foreign ion for incorporation into a mineral phase the empirical HendersonKracek partition coefficient (Henderson et al., 1928), $D$, is often used. It relates the composition of the solid to the composition of the aqueous solution. The composition of the solid is described by the mole fractions, $X_{i}$, of the endmember chemical components. To describe the composition of the aqueous solution the ion concentration product (ICP) of the two endmembers is used. Selenite incorporation into calcite can be described with the aid of the host (calcite, $\left.\mathrm{CaCO}_{3}\right)$ and the solute $\left(\mathrm{CaSeO}_{3}\right)$ endmembers, such that $\mathrm{X}$ (calcite) $+\mathrm{X}\left(\mathrm{CaSeO}_{3}\right)=1$. The corresponding ICPs are;

150

$\mathrm{ICP}\left(\mathrm{CaSeO}_{3}\right)=\mathrm{c}\left(\mathrm{Ca}^{2+}\right) \cdot \mathrm{c}\left(\mathrm{SeO}_{3}{ }^{2-}\right)$

$\mathrm{ICP}($ calcite $)=\mathrm{c}\left(\mathrm{Ca}^{2+}\right) \cdot \mathrm{c}\left(\mathrm{CO}_{3}{ }^{2-}\right)$

where $c_{i}$ are the concentrations of the ions in solution. The partition coefficient, $D$, is given by:

At equilibrium conditions, the partition coefficient can be related to thermodynamic properties of the endmembers (Glynn, 2000; Shtukenberg et al., 2006). Equilibrium states between aqueous and solid solution are defined through the ion activity products (IAP) of the endmember constituents;

$\operatorname{IAP}\left(\mathrm{CaSeO}_{3}\right)=\mathrm{a}\left(\mathrm{Ca}^{2+}\right) \mathrm{a}\left(\mathrm{SeO}_{3}{ }^{2-}\right)=\operatorname{ICP}\left(\mathrm{CaSeO}_{3}\right) \gamma\left(\mathrm{CaSeO}_{3}\right)$

$\operatorname{IAP}($ calcite $)=\mathrm{a}\left(\mathrm{Ca}^{2+}\right) \mathrm{a}\left(\mathrm{CO}_{3}{ }^{2-}\right) \quad=\operatorname{ICP}($ calcite $) \gamma($ calcite $)$

where $a_{i}$ are the activities of the ions in solution. $\gamma_{i}$ are the corresponding products of all relevant aqueous solution activity coefficients. In such a system the IAPs would be linked to the solubility products $\left(\mathrm{K}_{\mathrm{SP}}\right)$ of the endmember phases by;

$\operatorname{IAP}\left(\mathrm{CaSeO}_{3}\right)=\mathrm{K}_{\mathrm{SP}}\left(\mathrm{CaSeO}_{3}\right) \times\left(\mathrm{CaSeO}_{3}\right) \mathrm{f}\left(\mathrm{CaSeO}_{3}\right)$

with the solid solution activity coefficients, $\mathrm{f}_{\mathrm{i}}$. the solubility products of the endmember phases:

$\mathrm{D}=\frac{\mathrm{K}_{\mathrm{SP}}(\text { calcite }) \mathrm{f}(\text { calcite }) \gamma\left(\mathrm{CaSeO}_{3}\right)}{\mathrm{K}_{\mathrm{SP}}\left(\mathrm{CaSeO}_{3}\right) \mathrm{f}\left(\mathrm{CaSeO}_{3}\right) \gamma(\text { calcite })}$

For binary solid solutions that do not involve coupled substitution mechanisms, as in the case considered here, charges of the ions involved in the substitution mechanism are equal. Furthermore, at low ionic strength no ion specific aqueous activity coefficients need to be considered. Therefore, $\gamma\left(\mathrm{CaSeO}_{3}\right)=$ $\gamma$ (calcite) and equation (5) simplifies to: 
172

$\mathrm{D}=\frac{\mathrm{K}_{\mathrm{SP}}(\text { calcite }) \mathrm{f}(\text { calcite })}{\mathrm{K}_{\mathrm{SP}}\left(\mathrm{CaSeO}_{3}\right) \mathrm{f}\left(\mathrm{CaSeO}_{3}\right)}$

173

174

175

176

177

178

179

180

181

182

183

184

185

186

187

188

189

190

191

192

193

194

195

196

197

198

199

200

201

202

203

204

205

206 by;

and;
Considering that concentrations of $\mathrm{CaSeO}_{3}$ in the solid solution are relatively small $(<7 \%)$ a further simplification is possible. At low concentrations of the solute phase Henry's law $\left(\mathrm{f}\left(\mathrm{CaSeO}_{3}\right)=\right.$ constant; $\mathrm{f}$ (calcite) $=1$ ) can be applied. As the solubility product of the $\mathrm{CaSeO}_{3}$ endmember in the calcite structure and its activity coefficient are unknown, it is convenient to combine these two unknown variables by defining a hypothetical virtual $\mathrm{CaSeO}_{3}$ endmember via the equation:

$\mathrm{D}=\frac{\mathrm{K}_{\mathrm{SP}}(\text { calcite })}{\mathrm{K}_{\mathrm{SP}}\left(\mathrm{CaSeO}_{3_{\text {_virtual }}}\right)}=$ const.

This simplification is valid if the partition coefficient is constant over the range of solid solution compositions considered.

The Gibbs free energies of the endmember phases are related to their corresponding solubility products

$\mathrm{G}^{0}\left(\mathrm{CaSeO}_{3}\right.$ virtual $)=\mathrm{RT} \ln \left(\mathrm{K}_{\mathrm{SP}}\left(\mathrm{CaSeO}_{3 \_ \text {virtual }}\right)\right)+\mathrm{G}\left(\mathrm{Ca}^{2+}{ }_{(\mathrm{aq})}\right)+\mathrm{G}\left(\mathrm{SeO}_{3}{ }^{2-}{ }_{\text {(aq) }}\right)$

$\mathrm{G}^{0}($ calcite $)=\mathrm{RT} \ln \left(\mathrm{K}_{\mathrm{SP}}(\right.$ calcite $\left.)\right)+\mathrm{G}\left(\mathrm{Ca}^{2+}{ }_{(\mathrm{aq})}\right)+\mathrm{G}\left(\mathrm{CO}_{3}{ }^{2-}{ }_{(\mathrm{aq})}\right)$

where $G_{i}$ denotes the Gibbs free energies of formation (all relevant values used in this study are listed in Table 3 ), while $R$ and $T$ are the universal gas constant and the absolute temperature $(=298.15 \mathrm{~K})$, respectively. Eqns. (5b), (6a), and (6b) can be used to express the partition coefficient directly in terms of the Gibbs free energies of formation:

$\mathrm{D}=\exp \left[\left(\mathrm{G}^{0}(\right.\right.$ calcite $)-\mathrm{G}^{0}\left(\mathrm{CaSeO}_{3}\right.$ virtual $\left.\left.)-\mathrm{G}^{0}\left(\mathrm{CO}_{3}{ }^{2-}{ }_{\text {(aq) }}\right)+\mathrm{G}^{0}\left(\mathrm{SeO}_{3}{ }^{2-}{ }_{(\mathrm{aq})}\right)\right) /(\mathrm{RT})\right]$

The subscript "virtual" is used here to emphasize that the structure of this endmember cannot be crystallographically defined. The virtual endmember is a purely mathematical construction. Consequently, its solubility product cannot be directly measured. However, as we show below, the Gibbs free energy of the virtual endmember can be accurately computed by applying the Single Defect Method.

Eqns. (4) to (7) are based on the condition of thermodynamic equilibrium. This implies that the aqueous solution is saturated with respect to the solid phase. However, the coprecipitation experiments used in this study to quantify the uptake of selenite by calcite were run at supersaturated steady state conditions. To be able to treat the steady state experiment within the equilibrium thermodynamic concept we assume that the supersaturated solution remains in true equilibrium with an infinitesimally thin layer of precipitated calcite. This assumption is consistent with the concept of Astilleros et al. (2003) that the aqueous solution is in thermodynamic equilibrium with an infinitely small precipitate, whose composition corresponds to the highest value of the supersaturation function. This thin layer of calcite is treated here as a phase, which is named hereafter the surface solid solution. The thermodynamic description of this phase requires definition and characterization of the standard thermodynamic properties of the surface endmember and the determination of its excess Gibbs free energy. The thermodynamic properties of the surface endmember differ from the properties of its bulk analogue due 
to the influence of surface tension and interfacial energy effects. Below we show that for the quantification of surface incorporation only the difference in the Gibbs free energies of the virtual surface endmembers is required and that this thermodynamic quantity can be computed both from experimental data or from first principles.

The concept developed here is similar to the model of surface enrichment and entrapment during calcite growth presented by Watson (2004). Here a value equivalent to Watson's surface enrichment factor is defined based on atomistic calculations and experimental data. However, our model avoids any kinetic variables and is purely based on equilibrium thermodynamics. In essence, we assume that thermodynamic equilibrium exists between the bulk aqueous solution and a thin surface layer of calcite. Layers that are entrapped under the surface layer are assumed to be out of equilibrium. Below, we will show that diffusion of selenite out of the entrapped layers of calcite plays a negligible role at room temperature and for the growth rates under consideration.

\subsection{The Single Defect Method (SDM) for the "bulk" solid solution}

The Single Defect Method of Sluiter and Kawazoe (2002) has recently been successfully applied to the modeling of isostructural solid solutions of barite and aragonite type crystal structures (Vinograd et. al, 2013). It has been shown that a dilute solid solution obeys the regular mixing model, while the slope of the enthalpy of mixing in an isostructural solid solution, measured at the trace composition limit, is equal to the Margules parameter. It has also been shown that the slope can be accurately predicted with the aid of first principles methods from the excess enthalpy of a supercell structure containing a single substitutional defect of the solute phase. Such a treatment is based on the assumption that the excess Gibbs free energy of a regular solid solution can be approximated by its excess enthalpy. The latter condition is particularly valid at low temperatures. In this section we develop a modified version of the SDM, which is specifically designed for non-isostructural solid solutions. Indeed, the solid solution between calcite and $\mathrm{CaSeO}_{3}$ cannot exist in the calcite structure over the whole range of mole fractions. The existing stable phase of $\mathrm{CaSeO}_{3}$ composition crystallizes in the space group $\mathrm{P} 2_{1} / \mathrm{n}$ (Wildner and Giester, 2007). Thus the excess free energy of mixing of the non-isostructural solid solution should have an inflection at an intermediate composition due to the structural transformation. The thermodynamic modeling of mixing functions of such a solid solution over the whole composition range is a very complicated task. Fortunately, the modeling of the whole range of the compositions is not required as we are interested in the thermodynamic properties of the solid solution only in the vicinity of the composition of the host phase. This is consistent with the definition of the virtual endmember via eqn. (5b) as a hypothetical phase, which forms an ideal solid solution with the host phase. The Gibbs free energy of this solid solution is defined to be indistinguishable from the free energy of the real solid solution in the Henry's law region.

The excess enthalpy of a solid solution in the dilute range can be modeled in an atomistic calculation as component. The excess enthalpy defines the slope of the excess mixing enthalpy relative to the mechanical mixture of calcite and the monoclinic $\mathrm{P}_{2} / \mathrm{n}$ phase of $\mathrm{CaSeO}_{3}$, here referred to as $\mathrm{CaSeO}_{3}$ 
(monocl.). Consequently, the slope includes the excess enthalpy of a hypothetical isostructural solid solution with the calcite structure and the enthalpy of the structural transition in the endmember phase from the trigonal to the monoclinic structure. Conveniently, the latter two quantities do not have to be known separately. The slope measured at $X=1$ defines the excess enthalpy of the virtual endmember relative to the monoclinic phase.

A supercell with a single defect simulates the solid solution with the composition $X=1 / n$, where $n$ is the number of cation - anion pairs (either $\mathrm{CaCO}_{3}$ or $\mathrm{CaSeO}_{3}$ ) in the supercell, which is equal to the number of calcium atoms, in the supercell. The excess enthalpy at the composition $X$ can be computed with the equation;

$\Delta \mathrm{H}^{\mathrm{E}}(1 / \mathrm{n})=\left[\mathrm{H}\left(\mathrm{Ca}_{n}\left(\mathrm{CO}_{3}\right)_{n-1} \mathrm{SeO}_{3}\right)-(\mathrm{n}-1) \mathrm{H}(\right.$ calcite $)-\mathrm{H}\left(\mathrm{CaSeO}_{3}\right.$ (monocl. $\left.\left.)\right)\right] / \mathrm{n}$,

where $\mathrm{H}$ (calcite) and $\mathrm{H}\left(\mathrm{CaSeO}_{3}\right.$ (monocl.)) are the total enthalpies of calcite and $\mathrm{CaSeO}_{3}$ (monocl.), respectively. A linear extrapolation of this difference from the mole fraction of $1 / n$ to 1 , effectively implies the multiplication of the excess value by $n$. Thus the excess enthalpy of the virtual $\mathrm{CaSeO}_{3}$ (bulk) endmember relative to the enthalpy of the monoclinic phase can be calculated as;

$\Delta \mathrm{H}^{\mathrm{E}}(1)=\mathrm{H}\left(\mathrm{Ca}_{\mathrm{n}}\left(\mathrm{CO}_{3}\right)_{\mathrm{n}-1} \mathrm{SeO}_{3}\right)-(\mathrm{n}-1) \mathrm{H}($ calcite $)-\mathrm{H}\left(\mathrm{CaSeO}_{3}\right.$ (monocl. $\left.)\right)$

The last quantity is defined per one mole of $\mathrm{CaSeO}_{3}$. This quantity completely determines the thermodynamic mixing properties of the virtual $\mathrm{CaSeO}_{3}$ endmember, and thus determines as well the properties of the dilute solid solution of $\mathrm{CaSeO}_{3}$ in $\mathrm{CaCO}_{3}$. This holds as long as the excess vibrational free energy of the solid solution is small. When this quantity cannot be neglected the excess Gibbs free energy of the virtual compound should be computed;

$\Delta \mathrm{G}^{\mathrm{E}}=\mathrm{G}\left(\mathrm{Ca}_{\mathrm{n}}\left(\mathrm{CO}_{3}\right)_{\mathrm{n}-1} \mathrm{SeO}_{3}\right)-(\mathrm{n}-1) \mathrm{G}^{0}$ (calcite) $-\mathrm{G}^{0}\left(\mathrm{CaSeO}_{3}\right.$ (monocl. $\left.)\right)$

In addition to the static excess enthalpy, $\Delta \mathrm{H}^{\mathrm{E}}, \Delta \mathrm{G}^{\mathrm{E}}$ includes excess properties derivable from the excess heat capacity, and the excess zero point energy. The evaluation of these effects requires the calculation of the phonon density of states of the reference phases and of the supercell. The evaluation of these properties based on DFT is possible, but is computationally very demanding for the large supercells used to capture realistic defect concentrations. The vibrational density of states can be also computed with the aid of a force-field model, if such a model is available or can be derived. The results of such calculations, which are described in the Results section, show that the vibrational terms make only a small contribution to the excess Gibbs free energy under the conditions of interest. The dominant part of the $\Delta \mathrm{G}^{\mathrm{E}}$ is represented by the $\Delta \mathrm{H}^{\mathrm{E}}$ term. Thus in the following text the vibrational contributions will be ignored and the assumption of $\Delta \mathrm{G}^{\mathrm{E}}=\Delta \mathrm{H}^{\mathrm{E}}$ will always be made, except for the case of the bulk solid solution, for which the vibrational effects will be explicitly calculated via a force-field model.

The absolute standard Gibbs free energy of the virtual endmember can be computed by adding $\Delta G^{\mathrm{E}}$ to the standard Gibbs free energy of the reference phase;

$\mathrm{G}^{0}\left(\mathrm{CaSeO}_{3}\right.$ virtual $)=\mathrm{G}^{0}\left(\mathrm{CaSeO}_{3}(\right.$ monocl. $\left.)\right)+\Delta \mathrm{G}^{\mathrm{E}}$ 
As we will show below, the Gibbs free energy of the virtual (bulk) $\mathrm{CaSeO}_{3}$ estimated with the SDM appears to be so large that the bulk solid solution with the calcite structure cannot contain a measurable fraction of $\mathrm{CaSeO}_{3}$. To be able to explain the rather high concentrations of $\mathrm{SeO}_{3}{ }^{2-}$ in calcite, which are observed in mixed flow reactor (MFR) coprecipitation experiments, we develop here a more complex thermodynamic model, which assumes a significant enrichment of the $\mathrm{CaSeO}_{3}$ in the surface layer of calcite and its continuous entrapment under stationary supersaturation conditions.

The thermodynamic description of this phase requires the determination of the standard thermodynamic properties of its endmembers. The endmembers of the surface solid solution can be defined by analogy with the bulk solid solution. The $\mathrm{CaCO}_{3}$ endmember can be associated with the surface layer of calcite. The atomistic modeling of this layer requires construction of a supercell of calcite, which contains a surface. This surface is implemented in DFT calculations by inserting a sufficiently thick vacuum layer into a 3D periodic supercell. The surface $\mathrm{CaSeO}_{3}$ endmember can be defined as a virtual endmember by computing the enthalpy of a similar supercell with one $\mathrm{CO}_{3}{ }^{2-}$ unit in the surface layer substituted with a $\mathrm{SeO}_{3}{ }^{2-}$ unit. The obvious difficulty of such a model is that the surface layer can be simulated only with the substratum of bulk-like calcite layers below the surface. While one can compute the free energy of the whole supercell, this creates the difficulty of how this energy should be separated into the energy of the surface layer and the energy of the quasi-bulk region. For pure phases this difficulty is usually dealt with by the consideration of surface free energy. In our case this difficulty implies that the absolute energies of the surface endmembers cannot be computed. Here we show that the absolute free energies of the surface endmembers are fortunately not required. The distribution coefficient depends just on the difference in the free energies of the $\mathrm{CaCO}_{3}$ and $\mathrm{CaSeO}_{3}$ surface endmembers, and this difference can be computed easily. Combining Eqns. (7) and (11) we obtain;

$D_{\text {bulk }}=\exp \left[\left(G^{0}\right.\right.$ (calcite) $-G^{0}\left(\mathrm{CaSeO}_{3}\right.$ monocl. $)-\Delta \mathrm{G}^{\mathrm{E}}$ bulk $^{-} \mathrm{G}^{0}\left(\mathrm{CO}_{3}{ }^{2-}\right.$ (aq) $)+\mathrm{G}^{0}\left(\mathrm{SeO}_{3}{ }^{2-}\right.$ (aq) $\left.\left.)\right) /(\mathrm{RT})\right]$

Eqn. (12) shows that, provided that the standard Gibbs free energies of calcite, $\mathrm{CaSeO}_{3}$ (monocl.), $\mathrm{CO}_{3}{ }^{2-}$ (aq) , and $\mathrm{SeO}_{3}{ }^{2-}{ }_{\text {(aq) }}$ are known, the distribution coefficient is determined by the single value of $\Delta \mathrm{G}^{\mathrm{E}}=\Delta \mathrm{G}^{\mathrm{E}}$ bulk. An analogous equation can be defined for the surface solid solution;

$D_{\text {surface }}=\exp \left[\left(G^{0}\right.\right.$ (calcite $)-G^{0}\left(\mathrm{CaSeO}_{3}\right.$ monocl. $\left.)-\Delta \mathrm{G}_{\text {surface }}^{\mathrm{E}}-\mathrm{G}^{0}\left(\mathrm{CO}_{3}{ }^{2-}{ }_{(\mathrm{qq})}\right)\right)+\mathrm{G}^{0}\left(\mathrm{SeO}_{3}{ }^{2-}\right.$ (aq) $\left.\left.)\right) /(\mathrm{RT})\right]$

Here we note that $\Delta \mathrm{G}_{\mathrm{i}}^{\mathrm{E}}$ in Eqns. (12) and (13) in fact defines the difference between the free energies of two $\mathrm{CaCO}_{3}$ and $\mathrm{CaSeO}_{3}$ endmembers in a given phase ( $\mathrm{i}=$ surface or bulk), relative to the difference of the free energies of the $\mathrm{CaCO}_{3}$ and $\mathrm{CaSeO}_{3}$ reference compounds, calcite and $\mathrm{CaSeO}_{3}$ (monocl.). Thus the $\Delta \mathrm{G}_{\text {bulk }}^{\mathrm{E}}$ in Eqn. (12) can be understood as;

$\Delta \mathrm{G}_{\text {bulk }}^{\mathrm{E}}=\left[\mathrm{G}^{0}\left(\mathrm{CaSeO}_{3}(\right.\right.$ virt., bulk $\left.)\right)-\mathrm{G}^{0}\left(\mathrm{CaCO}_{3}(\right.$ bulk $\left.\left.)\right)\right]-\left[\mathrm{G}^{0}\left(\mathrm{CaSeO}_{3}(\right.\right.$ monocl. $\left.)\right)-\mathrm{G}^{0}\left(\mathrm{CaCO}_{3}(\right.$ calcite $\left.\left.)\right)\right]$.

315 For the case of the bulk solid solution eqn. (14) is equivalent to eqn. (10) as $\mathrm{G}^{0}\left(\mathrm{CaCO}_{3}(\right.$ calcite) $)=$ 316 $\mathrm{G}^{0}\left(\mathrm{CaCO}_{3}(\right.$ bulk)). Combining Eqns. (10) and (11) we find that;

$\mathrm{G}^{0}\left(\mathrm{CaSeO}_{3}(\right.$ virt., bulk $\left.)\right)-\mathrm{G}^{0}\left(\mathrm{CaCO}_{3}(\right.$ bulk $\left.)\right)=\mathrm{G}^{0}\left(\mathrm{Ca}_{n}\left(\mathrm{CO}_{3}\right)_{n-1} \mathrm{SeO}_{3}\right)-\mathrm{G}^{0}\left(\mathrm{Ca}_{n}\left(\mathrm{CO}_{3}\right)_{n}\right)$ 
where the right hand part of the equation is represented by a supercell of calcite in which one $\mathrm{CO}_{3}{ }^{2-}$ unit is substituted with a $\mathrm{SeO}_{3}{ }^{2-}$ unit and a supercell of pure calcite.

In the case of the surface solution an equation analogous to eqn. (14) takes the form:

$\Delta \mathrm{G}_{\text {surface }}^{\mathrm{E}}=\left[\mathrm{G}^{0}\left(\mathrm{CaSeO}_{3}\right.\right.$ (virt., surface $\left.)\right)-\mathrm{G}^{0}\left(\mathrm{CaCO}_{3}(\right.$ surface $\left.\left.)\right)\right]-\left[\mathrm{G}^{0}\left(\mathrm{CaSeO}_{3}(\right.\right.$ monocl. $\left.)\right)-\mathrm{G}^{0}\left(\mathrm{CaCO}_{3}\right.$ (calcite $\left.\left.)\right)\right]$

In the particular case of the bulk solid solution, the $\mathrm{CaCO}_{3}$ (bulk) endmember coincides with $\mathrm{CaCO}_{3}$ (calcite). Due to this simplifying circumstance we can, in fact, compute the absolute free energy of the virtual bulk $\mathrm{CaSeO}_{3}$ endmember (eqn. (11)). A similar simplification is not possible in the case of the surface solid solution. However, this is not a problem as the distribution coefficient depends only on the difference between the free energies of the surface endmembers, $\mathrm{CaCO}_{3}$ (surface) and $\mathrm{CaSeO}_{3}$ (virt., surface). Analogously to eqn. (15) it is possible to show that;

$\mathrm{G}^{0}\left(\mathrm{CaSeO}_{3}\right.$ (virt., surface $\left.)\right)-\mathrm{G}^{0}\left(\mathrm{CaCO}_{3}(\right.$ surface $\left.)\right)=\mathrm{G}^{0}\left(\mathrm{Ca}_{\mathrm{n}}\left(\mathrm{CO}_{3}\right)_{\mathrm{n}-1} \mathrm{SeO}_{3}\right)^{*}-\mathrm{G}^{0}\left(\mathrm{Ca}_{\mathrm{n}}\left(\mathrm{CO}_{3}\right)_{\mathrm{n}}\right)^{*}$,

where * denotes supercells including a free surface. This leads to a rigorous definition of $\Delta \mathrm{G}_{\text {surface }}^{\mathrm{E}}$ as;

$\Delta \mathrm{G}_{\text {surface }}^{\mathrm{E}}=\left[\mathrm{G}^{0}\left(\mathrm{Ca}_{n}\left(\mathrm{CO}_{3}\right)_{\mathrm{n}-1} \mathrm{SeO}_{3}\right)^{*}-\mathrm{G}^{0}\left(\mathrm{Ca}_{n}\left(\mathrm{CO}_{3}\right)_{n}\right)^{*}\right]-\left[\mathrm{G}^{0}\left(\mathrm{CaSeO}_{3}(\right.\right.$ monocl. $\left.)\right)-\mathrm{G}^{0}\left(\mathrm{CaCO}_{3}(\right.$ calcite $\left.\left.)\right)\right]$

In our study the $\Delta \mathrm{G}^{\mathrm{E}}$ surface parameter is computed with the aid of a supercell composed of a slab of 5 calcite layers parallel to (104) and a vacuum layer (which may or may not additionally contain water molecules) of equivalent thickness (see section 3.3 for further details). Each calcite layer consists of 8 $\mathrm{CaCO}_{3}$ units, such that the slab contains in total $40 \mathrm{CaCO}_{3}$ units, 16 of which are at the surface. Two supercells with one $\mathrm{SeO}_{3}{ }^{2-}$ unit at the surface are shown in the Supplementary Information Figure S2.

\subsection{Estimation of the standard Gibbs free energy of the monoclinic $\mathrm{CaSeO}_{3}$}

The monoclinic $\mathrm{P} 2_{1} / \mathrm{n}$ phase is the only compound of $\mathrm{CaSeO}_{3}$ composition for which the crystal structure is available (Wildner and Giester, 2007). This phase serves perfectly as the reference compound. However, its thermodynamic properties are unknown. Here we make an attempt to estimate the standard Gibbs free energy of the $\mathrm{CaSeO}_{3}$ (monocl.) from the total energy changes in the reactions:

$\mathrm{BaSeO}_{3}+\mathrm{CaCO}_{3}$ (aragonite) $\rightarrow \mathrm{CaSeO}_{3}+\mathrm{BaCO}_{3}$

$\mathrm{SrSeO}_{3}+\mathrm{CaCO}_{3}$ (aragonite) $\rightarrow \mathrm{CaSeO}_{3}+\mathrm{SrCO}_{3}$

345 The standard free energies of all phases involved in eqns. (17) and (18), except for $\mathrm{CaSeO}_{3}$, are known 346 (Table 3). If we know the free energies of these reactions, we can compute the free energy of $\mathrm{CaSeO}_{3}$ 347 (monocl.). As the structures of the reactants and products are similar, and the temperature of interest $348(298.15 \mathrm{~K})$ is small, we assume that entropy effects are negligible. Thus we can approximate the free energy changes in these reactions as the changes in the total energy. 
353 Various crystal growth methods are applied to synthesize selenite-doped calcite. Mixed flow reactor 354 experiments are used to examine the incorporation at surface controlled growth conditions. In MFR 355 experiments the selenite concentration is varied from $2 \cdot 10^{-13} \mathrm{~mol} / \mathrm{L}$ to $2 \cdot 10^{-4} \mathrm{~mol} / \mathrm{L}$ in order to measure 356 the partition coefficient and growth rate as a function of selenite concentration. $A$ batch type crystal growth experiment at $0.001 \mathrm{~mol} / \mathrm{L} \mathrm{SeO}_{3}{ }^{2-}$ concentration is used to synthesize a $\mathrm{SeO}_{3}{ }^{2-}$ doped calcite single crystal, which is used for the polarization dependent Se K-edge EXAFS measurements. In order to investigate crystal growth even closer to equilibrium than in MFR experiments, aragonite to calcite recrystallization experiments are applied. The recrystallization rate of aragonite in a pure system is compared to that in the presence of $10^{-4} \mathrm{~mol} / \mathrm{L}$ selenite. In order to compare selenite coprecipitation at supersaturated conditions to selenite adsorption at equilibrium conditions batch type adsorption experiments are conducted. In the following sections the experiments will be described in detail.

\subsubsection{MFR experiments}

To grow calcite in an MFR experiment, the MFR is fed continuously with three independent input solutions; one containing $18 \mathrm{mmol} / \mathrm{L} \mathrm{Ca}^{2+}$, added as $\mathrm{CaCl}_{2} \cdot 2 \mathrm{H}_{2} \mathrm{O}$ pa., the next containing $9 \mathrm{mmol} / \mathrm{L}$ inorganic carbon, added as $\mathrm{NaHCO}_{3}$ pa., and the third containing the selenite. Solutions are prepared from purified water (18.2 M $\Omega,<2$ bbp dissolved organic carbon). All input solutions contain $0.01 \mathrm{~mol} / \mathrm{L}$ $\mathrm{NaCl}$ as a background electrolyte. Seed crystals are provided in the reactor. Merck calcium carbonate suprapure is used for seed crystals. Powder X-ray diffraction on a Bruker D8 Advance showed that the seed crystals consist of pure calcite to within the level of uncertainty ( $\pm 0.5 \%$ ). The specific surface area of the calcite seeds measured by $\mathrm{N}_{2}$-BET is $0.51 \pm 0.04 \mathrm{~m}^{2} / \mathrm{g}$. XPS C1s spectra confirmed that the contamination of the Merck calcium carbonate suprapure with adventitious carbon is relatively low compared to XPS data reported in literature (Stipp and Hochella, 1991); about $20 \%$ of the C1s spectrum is related to organic carbon while the rest is attributed to carbonate. The diameters of the seed crystals are in the range of 5 to $20 \mu \mathrm{m}$. The solution in the MFR is permanently agitated by a magnetic stirring bar, which is suspended to avoid grinding effects. The stirrer is rotated at $850 \mathrm{rpm}$. The size of the seed crystals and the rotation speed of the magnetic stirrer are chosen to minimize any boundary layer effects (Nielsen and Toft, 1984; Wang and Xu, 2001) and to ensure surface controlled crystal growth kinetics. MFR experiments were typically run for 14 days. After an initial period of elevated growth rate, steady state conditions establish in the MFR, and the selenite-doped calcite precipitates homogeneously onto the surface of the seed crystals. Perfect mixture is assumed inside the MFR; therefore the solution composition in the outlet is considered representative of the solution composition in the reactor. To monitor the progress of the reaction, samples of the outlet solution were taken on a daily basis. With each sampling the exact pump rate, $\mathrm{F}$, was measured and the $\mathrm{pH}$ was checked. The sample was acidified and stored for further analysis of the $\mathrm{Ca}^{2+}$ and $\mathrm{SeO}_{3}{ }^{2-}$ concentrations. $\mathrm{Ca}^{2+}$ concentrations were measured on a Perkin Elmer Optima 2000 DV inductively coupled plasma optical emission spectrometer (ICP-OES). A spike of $13 \mathrm{kBq} / \mathrm{L}$ of radioactive ${ }^{75} \mathrm{SeO}_{3}{ }^{2-}$ was added to the solution reservoir containing the nonradioactive selenite. Carrier free ${ }^{75} \mathrm{SeO}_{3}{ }^{2-}$ was purchased from Eckert \& Ziegler Nuclitec GmbH. It has a 391 half-life of 120 days and the concentration was analyzed by gamma-spectroscopy. Selenite concentration 
after the reactor was calculated assuming that the percentage reduction of the ${ }^{75}$ Se concentration in the MFR is representative of the reduction in total selenite concentration. The decrease in calcium concentration is taken as a measure of calcite growth inside the MFR. It is assumed that the combined total inorganic carbon concentration and selenium concentration decreases by the same amount as the calcium concentration in the MFR due to calcite precipitation. The calcite growth rate, $R_{c a}$, in the MFR can be calculated according to;

$R_{c a}=\frac{\Delta c\left(\mathrm{Ca}^{2+}\right) \cdot \mathrm{F}}{\mathrm{A}}$

where ' $A$ ' is the reactive surface area of the calcite seeds in the MFR, which is assumed to remain constant during the MFR experiment. The mole fraction of $\mathrm{CaSeO}_{3}$ in the precipitated solid can be calculated from;

$\mathrm{X}\left(\mathrm{CaSeO}_{3}\right)=\frac{\Delta \mathrm{c}\left(\mathrm{SeO}_{3}{ }^{2-}\right)}{\Delta \mathrm{c}\left(\mathrm{Ca}^{2+}\right)}$,

while $\mathrm{X}$ (calcite) $=1-\mathrm{X}\left(\mathrm{CaSeO}_{3}\right)$. Partition coefficients are then calculated according to eqn. (2), which simplifies to:

$\mathrm{D}=\mathrm{X}\left(\mathrm{CaSeO}_{3}\right) / \mathrm{X}($ calcite $) \cdot \mathrm{c}\left(\mathrm{CO}_{3}{ }^{2-}\right) / \mathrm{c}\left(\mathrm{SeO}_{3}{ }^{2-}\right)$

It is important to note that the composition of the solid, represented by $\mathrm{X}\left(\mathrm{CaSeO}_{3}\right) / \mathrm{X}($ calcite $)$, is related to the molalities of the free $\mathrm{CO}_{3}{ }^{2-}$ and $\mathrm{SeO}_{3}{ }^{2-}$ species in solution and not the total element concentrations. Species distributions, as well as saturation indices, were calculated using PhreeqC (Parkhurst and Appelo, 1999) and the Nagra/PSI thermodynamic database (Hummel et al., 2002). During all MFR experiments the solutions were undersaturated with respect to $\mathrm{CaSeO}_{3} \cdot \mathrm{H}_{2} \mathrm{O}(\mathrm{SI}<-0.4)$, the selenite phase most likely to precipitate from aqueous solution at standard conditions (Olin et al., 2005).

Ten MFR experiments were conducted for the present study; seven using ${ }^{75} \mathrm{SeO}_{3}{ }^{2-}$, to quantify the selenite coprecipitation, one using only non-radioactive selenite, to produce an inactive selenite-doped calcite powder for EXAFS measurements, and two growing pure calcite in order to obtain reference growth rates in pure calcite systems.

Using $\mathrm{NaHCO}_{3}$ as the carbonate source, the $\mathrm{pH}$ during the precipitation reaction was in the range 7.3 to 8.0. This $\mathrm{pH}$ region was chosen as it has been previously reported that selenite adsorption on calcite is preferred at lower $\mathrm{pH}$ (Cowan et al., 1990). In this $\mathrm{pH}$ region a high calcium concentration $(0.006 \mathrm{~mol} / \mathrm{L}$ ) has to be used to achieve the desired calcite supersaturation. The combination of high calcium concentration and low growth rate resulted in a very low percentage difference in calcium concentration between input and output solutions. In many cases the interpretation of the MFR data is limited by the analytical uncertainty of the ICP-OES measurements of the calcium concentration. MFR experiments for which the difference between calcium input and output concentration is significant (larger than uncertainty) are labeled with $(\triangle \mathrm{Ca})$ in Table 1 . For the other MFR experiments (labeled with $(\Delta \mathrm{pH})$ in Table 1) the amount of precipitated calcite was calculated with PhreeqC based on the $\mathrm{pH}$ difference between a 1:1:1 mixture of the three input solutions and the average $\mathrm{pH}$ of the output solution. 
Errors in the surface area were derived from the estimated analytical uncertainty for $\mathrm{N}_{2}$-BET measurements, which is $9 \%$. Errors for the measured values of $\mathrm{pH}$ and $\mathrm{F}$ in Table 1, but also calcium and the calculated values, $\mathrm{R}_{\mathrm{ca}}, \mathrm{c}(\mathrm{Se}), \Delta \mathrm{c}\left(\mathrm{Ca}^{2+}\right), \Delta \mathrm{c}\left(\mathrm{SeO}_{3}{ }^{2-}\right), \mathrm{X}\left(\mathrm{CaSeO}_{3}\right), \mathrm{X}$ (calcite), and $\mathrm{D}$, error propagation calculations were applied to estimate the standard deviations, based on all experimental uncertainties. For values calculated using PhreeqC, like $\mathrm{SI}($ calcite $), \mathrm{c}_{\left(\mathrm{CO}_{3}{ }^{2-}\right)}$, and $\mathrm{c}\left(\mathrm{SeO}_{3}{ }^{2-}\right)$, uncertainties were estimated by calculating a bandwidth of possible results. Therefore the input values were varied about their standard deviations and the highest and lowest results obtained are taken as the standard deviation of the resulting values. Uncertainties in the relevant equilibrium constants are not considered.

\subsubsection{Preparation of a selenite doped calcite single crystal}

For the preparation of a selenite-doped single crystal a batch type crystal growth experiment was performed. Initially a $0.1 \mathrm{~mol} / \mathrm{L} \mathrm{NaCl}$ solution in equilibrium with calcite and atmospheric $\mathrm{CO}_{2}$ was prepared. Here calcite powder was added to a $0.1 \mathrm{~mol} / \mathrm{L} \mathrm{NaCl}$ solution that was continuously stirred and percolated with air until the calculated equilibrium $\mathrm{pH}$ value 8.2 was reached. Then the solution was Mexico Chihuahua was freshly cleaved along the crystallographic (104) plane to obtain an optically flat crystal surface. Directly after cleavage the crystal was immersed in the filtered equilibrium solution. Then $\mathrm{NaOH}$ and $\mathrm{Na}_{2} \mathrm{SeO}_{3}$ stock solutions were added to reach a concentration of $0.001 \mathrm{~mol} / \mathrm{L} \mathrm{NaOH}$ and $0.0001 \mathrm{~mol} / \mathrm{L} \mathrm{Na}_{2} \mathrm{SeO}_{3}$ in the reaction vessel. This caused an increase in $\mathrm{pH}$ to a value of 10 , and, according to PhreeqC calculations, corresponds to an $\mathrm{SI}$ (calcite) of 1.2. After the addition of $\mathrm{NaOH}$ and $\mathrm{Na}_{2} \mathrm{SeO}_{3}$ the vessel was sealed to avoid further reaction with air. After six days the solution reached a $\mathrm{pH}$ of 9.8. This indicates that the SI(calcite) had decreased to a value of about 0.7 and about $4 \cdot 10^{-4} \mathrm{~mol} / \mathrm{L}$ calcite precipitated. Taking into account the $20 \mathrm{~mL}$ solution volume and the reactive surface area of the single crystal of about $3 \mathrm{~cm}^{2}$, this corresponds to roughly $0.03 \mathrm{~mol} / \mathrm{m}^{2}, 3,000$ monolayers, or $1 \mu \mathrm{m}$, of calcite precipitation onto the single crystal surface. The selenite-doped calcite single crystal was analyzed by polarization dependent EXAFS measurements.

\subsubsection{Aragonite recrystallization experiments}

For aragonite recrystallization experiments $1 \mathrm{~g}$ of aragonite was added to $50 \mathrm{~mL}$ of $0.1 \mathrm{~mol} / \mathrm{L} \mathrm{NaCl}$ solution. Recrystallization rates of a pure aragonite experiment were compared to an experiment where an additional $10^{-4} \mathrm{~mol} / \mathrm{L} \mathrm{Na}_{2} \mathrm{SeO}_{3}$ is added. The essential idea behind these experiments is that, due to the difference between the solubility products of aragonite $\left(\log _{10} \mathrm{~K}_{S P}=-8.34\right)$ and calcite $\left(\log _{10} \mathrm{~K}_{S P}=-8.48\right)$, an aragonite equilibrated solution intrinsically has $\mathrm{SI}$ (calcite) $=0.14$. Therefore it is expected that aragonite dissolves slowly and calcite precipitates at a very low supersaturation. The reaction progress of the recrystallization experiment was monitored by pipetting a $5 \mathrm{~mL}$ aliquot of the suspension onto a $0.45 \mu \mathrm{m}$ filter membrane, drying the obtained powder at $105^{\circ} \mathrm{C}$ over-night, and analyzing it by powder XRD. Powder XRD measurements were performed on a Bruker D8 Advance diffractometer. Rietveld analysis of diffractograms was performed using the Bruker AXS DiffracPlus Topas 4.2 software. 
A self-synthesized sample of aragonite was used for the experiments. Aragonite was synthesized according to a method after Ogino et al. (1987), by mixing equal amounts of $0.5 \mathrm{~mol} / \mathrm{L} \mathrm{Na}{ }_{2} \mathrm{CO}_{3}$ and 0.5 $\mathrm{mol} / \mathrm{L} \mathrm{CaCl} \cdot 2 \mathrm{H}_{2} \mathrm{O}$ solution at $90^{\circ} \mathrm{C}$. After two to three minutes the precipitated powder is separated from the solution by filtration, dried at $105^{\circ} \mathrm{C}$ over-night, and analyzed by powder XRD, $\mathrm{N}_{2}$-BET and SEM. According to the Rietveld analysis of powder diffractograms, the obtained powder consists of $>97 \%$ aragonite, with some vaterite $(<3 \%)$, and traces of halite and calcite $(<0.3 \%)$. The specific surface area of the aragonite powder was $4.2 \mathrm{~m}^{2} / \mathrm{g}$, and consisted of $1-10 \mu \mathrm{m}$ sized needle like aggregates.

\subsubsection{Adsorption experiments}

In order to compare selenite coprecipitation at supersaturated conditions to selenite adsorption at equilibrium conditions, adsorption experiments were conducted. Selenium adsorption was studied using batch-type experiments. Solutions were prepared from purified water $(18.2 \mathrm{M} \Omega \cdot \mathrm{cm},<2 \mathrm{ppb} \mathrm{TOC})$ equilibrated with calcite and air $\left(\log _{10}\left(\mathrm{p}\left(\mathrm{CO}_{2}\right)\right)=-3.44\right)$. Reagent grade $\mathrm{HCl}$, or $\mathrm{NaOH}$, and $\mathrm{NaCl}$ were added to achieve an ionic strength of $0.1 \mathrm{~mol} / \mathrm{L}$ and the desired equilibrium $\mathrm{pH}$ in a range from 7.5 to 9.6. $25 \mathrm{~g} / \mathrm{L}$ Merck calcium carbonate suprapure, with a specific surface area of $0.51 \mathrm{~m}^{2} / \mathrm{g}\left(\mathrm{N}_{2}-\mathrm{BET}\right)$, was used as the crystal substrate (as in MFR experiments). Experiments were performed using radioactive ${ }^{75} \mathrm{SeO}_{3}{ }^{2-}$. The initial selenium(IV) concentration was $10^{-13} \mathrm{~mol} / \mathrm{L}$, and final Se-concentrations were analyzed by gamma-spectroscopy.

\subsection{Extended X-ray absorption fine structure (EXAFS) spectroscopy}

After the experiment, the selenite-doped calcite powder from MFR experiment, MFR Se EXAFS (see Table 1), was taken out of the MFR, dried and sealed between two layers of Kapton foil for fluorescence mode EXAFS measurements at the INE-beamline for actinide research at ANKA (Rothe et al., 2012). Eight Se Kedge X-ray absorption scans in an energy range from $12.508 \mathrm{keV}$ to $13.358 \mathrm{keV}$ (Se K-edge energy (Se 1s $\mathrm{Se}(0))$ at $12.658 \mathrm{keV}$ ) were recorded. Se $\mathrm{K} \alpha$ fluorescence was measured with a five pixel LEGe solid state detector (Canberra-Eurisys). For energy calibration, a selenium foil was measured in parallel behind the second ionization chamber in transmission mode, where the first inflection point is assigned to the $\operatorname{Se}(0)$ Se $1 \mathrm{~s}$ energy. Data treatment and analysis were performed using ATHENA and ARTEMIS from the IFEFFIT software package (Ravel and Newville, 2005). The $k^{3}$-weighted extracted XAFS signal was used in a $k$ range from 2.0 to $12.0 \AA^{-1}$. Hanning windows were applied in the Fourier Transformation. Data modeling was performed in $\mathrm{R}$ space in a range from 1.3 to $4.0 \AA$. Backscattering amplitude and phase shift functions, obtained from FEFF 6 (Ravel and Newville, 2005) calculations, were used as theoretical standards for modeling the data.

As synchrotron radiation is linearly polarized, with the polarization vector, $\vec{\varepsilon}$, perpendicular to the beam and in the plane of the storage ring, it is perfectly suited for polarization dependent experiments. For polarization dependent EXAFS measurements the selenite-doped single crystal, prepared as described above, was dried and mounted onto the goniometer at the INE-beamline. Beam-slits were used to obtain a rectangular shaped beam with $200 \mu \mathrm{m}$ vertical diameter by $\sim 500 \mu \mathrm{m}$ horizontal diameter. The sample 
with the (104) face of calcite on top was positioned in the beam at an incidence angle of the beam relative to the surface just above the critical angle of total external reflection for calcite, which is $0.152^{\circ}$ at $12.658 \mathrm{keV}$, the Se K-edge energy, to ensure a certain penetration depth of the beam into the sample. For a Figure explaining the experimental setup of the polarization dependent EXAFS measurements, see Supplementary Information Figure S1. The sample was slightly rocked during the energy scans, to account for the variation of the critical angle with the photon energy. The intensity of the beam behind the single crystal sample and the second ionization chamber was not high enough for the measurement of a reference spectrum for energy calibration. The energy was calibrated before the measurements and no drift was observed during the measurements. The sample was rotated around the surface normal to measure EXAFS spectra at three different orientations of the sample relative to the beam, or the polarization vector $\vec{\varepsilon}$, as shown in Figure S1b. The orientation labeled "bpa" corresponds to measurements with the beam approximately parallel to the crystallographic [42-1] direction and $\vec{\varepsilon}$ parallel to the [010] direction. The orientation labeled "bpb" corresponds to measurements with the beam offset by approximately $12^{\circ}$ from the [010] direction, which corresponds to $\vec{\varepsilon}$ being about parallel to the [43-1] direction. For the last orientation, labeled "bpk", the beam was parallel to the edge of the crystal, which corresponds to the [-441] direction. Therefore, $\vec{\varepsilon}$ was approximately parallel to the [46-1] direction during the "bpk" measurement (parallel or antiparallel does not matter for this experiment as will be explained later). Angles were only adjusted approximately using a laser alignment method. At each orientation 7 to 11 scans were recorded in an energy range from $12.458 \mathrm{keV}$ to $13.258 \mathrm{keV}$. For polarization dependent measurements the Se K $\alpha$ fluorescence was recorded using a silicon drift detector (SIINT Vortex EX-60), mounted looking directly down on to the sample surface (cf. Figure S1a).

EXAFS oscillations, $\chi$, are interpreted as being caused by interference between photoelectron waves going out from the absorbing atom (i) and scattered back from neighboring atoms $\left(u_{j}\right)$. Therefore they may be decomposed into contributions from successive atomic shells (j), composed of $N_{j}{ }^{\text {real }}$, atoms. For the atomic scale interpretation of the polarization dependent EXAFS data we follow the approach by Schlegel et al. (1999). In EXAFS data measured on a powder sample, the amplitude of the EXAFS signal attributed to the $\mathrm{j}^{\text {th }}$ shell, $\chi_{i j}{ }_{i j}^{\text {iso }}$, is proportional to the number of atoms in the $j^{\text {th }}$ shell, $\mathrm{N}_{\mathrm{j}}^{\text {real }}$. In a polarization dependent experiment the amplitude depends additionally on the angle between the vectors, $\vec{R}_{i u_{j}}$, connecting the absorbing atom (i) with the $\mathrm{u}_{\mathrm{j}}$ atoms in the $\mathrm{j}^{\text {th }}$ shell, and the polarization vector $\vec{\varepsilon}$. At K-edges, and in the plane wave approximation, the relationship between the isotropic EXAFS signal, $\chi_{i j}{ }^{\text {iso }}$, and the polarized EXAFS signal, $\chi_{i j}{ }^{p}$, can be expressed as (Schlegel et al., 1999):

$$
\chi_{\mathrm{ij}}^{\mathrm{P}}=3 \chi_{\mathrm{ij}}^{\mathrm{iso}} \sum_{\mathrm{u}_{\mathrm{j}}=1}^{\mathrm{N}_{\mathrm{j}}^{\mathrm{real}}} \cos ^{2} \theta_{\mathrm{iu}_{\mathrm{j}}}
$$

536 where $\theta_{i u_{j}}$ are the angles between the vectors $\vec{R}_{i u_{j}}$ and the polarization vector $\vec{\varepsilon}$. Only the amplitude of the EXAFS signal is modified by changes of the orientation of the sample relative to $\vec{\varepsilon}$. As the amplitude is 538 proportional to $\mathrm{N}_{\mathrm{j}}^{\text {real }}$, we can use this relation and retrieve from polarization dependent EXAFS data not the real coordination number, $\mathrm{N}_{\mathrm{j}}^{\text {real }}$, but an effective coordination number, $\mathrm{N}_{\mathrm{j}}^{\text {eff }}$.

540 Deviating from the approach by Schlegel et al. we do not relate the polarization dependent amplitude 541 variation to special angles relative to the crystal axes, but calculate the contribution of each neighboring 
542 atom to the polarization dependent EXAFS signal explicitly. In terms of an effective coordination number 543 the contribution of one single atom in the $\mathrm{j}^{\text {th }}$ shell, $\mathrm{u}_{\mathrm{j}}$, to the EXAFS amplitude can be expressed as:

545 The $\cos ^{2}$ dependence between $\theta$ and $\mathrm{N}^{\text {eff }}$ explains why it does not matter if a vector is parallel or 546 antiparallel to a certain crystallographic direction during the measurements. Taking the sum over all atoms in the $\mathrm{j}^{\text {th }}$ shell, we get the effective coordination number of the $\mathrm{j}^{\text {th }}$ shell as;

where $G$ is the metric tensor of the calcite lattice. Equation (23) enables us to refine an atomic scale structure from the polarization dependent EXAFS data that considers not only distances, but also the angular relations between the atoms and the polarization vectors. Real coordination numbers are equal to three in all cases in the relevant structure. The analysis of the polarization dependent EXAFS data is performed as a multiple dataset fit in ARTEMIS (Ravel and Newville, 2005), meaning that all polarization dependent EXAFS data are fitted simultaneously. The bond-distances and the Debye-Waller-factors are treated as global parameters (equal for all orientations). Individual parameters are used for the coordination numbers, $\mathrm{N}^{\mathrm{eff}}$, for each shell and orientation. Modeling is performed on $\mathrm{k}^{2}$-weighted EXAFS data. The limited signal to noise ratio, especially in the "bpk" data set, required the k-range to be limited to $2 \AA^{-1}$ to $9.4 \AA^{-1}$. Hanning windows are used for the Fourier transformation. Fitting is performed in Rspace, in an R-range from $1.3 \AA$ to $4.1 \AA$.

\subsection{Atomistic calculations}

In order to get an impression of the uncertainties involved in the single defect calculations, we have computed the enthalpy changes in eqns. (8) to (16) by applying different exchange-correlation functionals within Kohn-Sham DFT, and comparing the results. We have applied two functionals within the Generalized Gradient Approximation (Wu-Cohen (Wu and Cohen, 2006) and Perdew-Burke-Ernzerhof (Perdew et al., 1996)) and two methods of describing the influence of core electrons (ultrasoft pseudopotentials and the projector augmented wave approach). A short description of the various theoretical methods is given in the following subsections. A more detailed description of the DFT calculations and the resulting interface structures will be published elsewhere. Images of the supercells

\subsubsection{DFT calculations using the Wu-Cohen functional and ultrasoft pseudopotentials (WC-USP)}

573 This set of DFT calculations was performed with the CASTEP code (Clark et al., 2005). Here the electronic

574 wavefunctions of the valence electrons are expanded in a plane-wave basis set, while the combined 
were performed with the "on-the-fly-generated" ultrasoft pseudopotentials supplied with Materials Studio 6.0 (http://accelrys.com/products/materials-studio/). The exchange and correlation potential was treated with the Wu-Cohen (WC) functional ( $\mathrm{Wu}$ and Cohen, 2006). Brillouin zone sampling was performed according to the Monkhorst-Pack scheme (Monkhorst and Pack, 1976) with a separation between individual k-points of 0.03-0.035 $\AA^{-1}$. The calculations were performed with a plane-wave cutoff energy of $810 \mathrm{eV}$. The conversion tests were performed in the range of 710-1210 eV. Our tests have shown that with this cutoff of $810 \mathrm{eV}$ the differences in total energies, e.g. the energy effects of the reactions (17) and (18) are converged to within $0.001 \mathrm{eV}$.

The WC-USP calculations were used to calculate the enthalpy differences in eqns. 8-18. The enthalpies of the reactions, which involve supercells with water layers, were computed with different methods. The total energies of $\mathrm{CaSeO}_{3}$ (monocl.), $\mathrm{CaCO}_{3}$ (calcite, aragonite), $\mathrm{SrCO}_{3}$ and $\mathrm{BaCO}_{3}$ were computed with symmetry constraints consistent with the reported space groups of these compounds. The lattice parameters and the atomic coordinates were fully relaxed. The single defect calculations were performed with two different supercells. The substitution of the $\mathrm{SeO}_{3}{ }^{2-}$ in the bulk structure was studied with a $2 \times 2 \times 1$ supercell prepared from the hexagonal unit cell of calcite. One of the $24 \mathrm{CO}_{3}{ }^{2-}$ groups was replaced with $\mathrm{SeO}_{3}{ }^{2-}$ group, such that the initial coordinates of the three oxygen atoms were the same as in the removed $\mathrm{CO}_{3}{ }^{2-}$ group, while the Se atom is slightly displaced along the c-axis (Figure S2 (left)). The $\mathrm{SeO}_{3}{ }^{2-}$ substitution at the surface was investigated with a supercell composed of 5 layers of $\mathrm{CaCO}_{3}$ arranged parallel to the (104) direction and a vacuum layer with a thickness equivalent to $5 \mathrm{CaCO}_{3}$ layers. The $\mathrm{SeO}_{3}{ }^{2-}$ unit was located in the boundary layer replacing a $\mathrm{CO}_{3}{ }^{2-}$ unit such that the Se atom is shifted relative to the removed $\mathrm{C}$ atom away from the surface, as shown in Figure $\mathrm{S} 2$ in the middle. The supercell parameters and the coordinates of all atoms were relaxed in P1 symmetry. The geometries were optimized until the residual forces and stresses are less than $0.005 \mathrm{eV} / \AA$ and $0.1 \mathrm{GPa}$, respectively.

\subsubsection{DFT calculations using the Perdew-Burke-Ernzerhof functional and the projector augmented wave method (PBE-PAW)}

PBE-PAW calculations were carried out using the Vienna ab-initio simulation package, VASP (Kresse and Furthmuller, 1996a, b; Kresse and Hafner, 1993a, b, 1994), which similarly to CASTEP employs periodic boundary conditions and a plane-wave basis set. Electron exchange and correlation are described using the Perdew-Burke-Ernzerhof (PBE) functional (Perdew et al., 1996). The nuclei and core states are modeled with the projector augmented wave (PAW) method (Blochl, 1994) as described by Kresse and Joubert (Kresse and Joubert, 1999).

In contrast to the WC-USP setup, the bulk incorporation was modeled using a $2 \times 2 \times 2$ calcite supercell of monoclinic shape, whose vectors were chosen such that one face of the cell is parallel to (104) as was also used by Heberling et al. (2011). The other termination plains of this cell correspond to (010) and (421 ) in hexagonal coordinates. The different cell geometry was chosen to assess the possible effect of the size and shape of the supercell on the predicted $\Delta \mathrm{G}^{\mathrm{E}}$ of the virtual bulk $\mathrm{CaSeO}_{3}$ endmember.

The monoclinic $\mathrm{P} 2_{1} / \mathrm{n}$ structure (Wildner and Giester, 2007) of the $\mathrm{CaSeO}_{3}$ reference phase has been optimized to determine the electronic energy of the unit cell. The corresponding unit cell parameters are 
listed in Table S2. The energy cut-off of $650 \mathrm{eV}$ for the kinetic energy of the plane-waves was used in all calculations. The modeling of the $\mathrm{SeO}_{3}{ }^{2-}$ incorporation into the bulk of calcite employed complete optimization of the cell volume and the ionic positions.

The modeling of the $\mathrm{SeO}_{3}{ }^{2-}$ incorporation into the surface layer was done using the optimized calcite supercell of monoclinic shape consisting of $5 \mathrm{CaCO}_{3}$ layers. The supercell is similar to that used in the WC-USP setup. Above the $\mathrm{CaCO}_{3}$ layers a $15 \AA$ thick layer of vacuum was added, which is sufficient to isolate the five layers from their periodic images. The total energy was calculated first for the supercell of pure calcite and subsequently for a supercell, in which one surface $\mathrm{CO}_{3}{ }^{2-}$ unit is substituted with $\mathrm{SeO}_{3}{ }^{2-}$.

To explore the influence of partial hydration on the selenite surface substitution the surface calculations were repeated with supercells containing three layers of water molecules (Figure S2 (right)). These layers of water were inserted above the calcite vacuum interfaces. The water molecules of the first layer were located on top of the $\mathrm{Ca}^{2+}$ ions, while the molecules of the second layer were placed above the $\mathrm{CO}_{3}{ }^{2-}$ ions, in agreement with previous experimental (Heberling et al., 2011) and computational (Raiteri et al., 2010) studies. Initially the water molecules of the first two layers were arbitrarily oriented. The subsequent geometry optimization resulted in reorientation of the water molecules and in slight changes in the positions of the oxygen atoms. A well-ordered structure of the water layer is thus obtained. Then the third layer, consisting of 15 water molecules, was introduced on top of the second layer. This layer is intended to simulate the effect of bulk water on the first two layers, as motivated by our earlier work on corundum (Janecek et al., 2013). The geometry of the whole structure was then optimized. The optimization of three layers of water at the surface resulted in a water structure showing a periodicity of the water molecules along the [42-1] direction of calcite. Due to this periodicity, only each second $\mathrm{CO}_{3}{ }^{2-}$ group at the interface finds itself surrounded by an equivalent arrangement of water molecules (i.e. neighboring $\mathrm{CO}_{3}{ }^{2-}$ groups are surrounded by slightly different configurations of water). To simulate $\mathrm{CO}_{3}{ }^{2-}$ substitution by $\mathrm{SeO}_{3}{ }^{2-}$ at the calcite water-interface we subsequently substituted the two non-equivalent carbonate sites and optimized the surface supercell. The corresponding configurations will be subsequently referred to as Se1 and Se2.

\subsubsection{DFT calculations using the Perdew-Burke-Ernzerhof functional and ultrasoft pseudopotentials (PBE- USP and $P B E+D-U S P)$}

To assess whether any small differences between WC-USP and PBE-PAW calculations originate either from functionals or from pseudopotentials, the whole set of bulk and dry surface incorporation calculations was repeated with the PBE functional in combination with the "on-the-fly-generated" ultrasoft pseudopotentials supplied with Materials Studio 6.0 (http://accelrys.com/products/materialsstudio/). These calculations were again performed using the CASTEP code (Clark et al., 2005). Converged structures from WC-USP and PBE-PAW calculations are used as input configurations for these calculations. The plane-wave cutoff energy remained at $810 \mathrm{eV}$. As recent work has shown that the description of water in DFT calculations is improved by the inclusion of corrections for the long-range dispersion (Wang et al., 2011), the calculations of the $\mathrm{SeO}_{3}{ }^{2-}$ incorporation at the calcite-water interface were additionally studied with the PBE+D-USP method, where dispersion corrections are included 
according to the method of Tkatchenko and Scheffler (2009). As our previous calculations revealed periodicity in the structure of the water layer, the water-interface incorporation was modeled using $\mathrm{PBE}+\mathrm{D}$ for the two distinct sites, Se1 and Se2.

\subsubsection{Force-field calculations}

The entropy effects of the $\mathrm{SeO}_{3}{ }^{2-}$ substitution in the bulk structure have been investigated with the aid of a force-field model. The present model is based on the recent flexible carbonate model derived to yield thermodynamically accurate properties for calcium carbonate (Demichelis et al., 2011). Here this force field is extended to include the interactions within the $\mathrm{SeO}_{3}{ }^{2-}$ unit and the interactions between this anion with the surrounding host material, calcite. Intramolecular bonded parameters for the selenite group were determined by fitting to the quantum mechanically ( $Q M$ ) determined structure and vibrational modes for the isolated ion. These QM calculations were performed at the M06/cc-pVDZ level of theory (Zhao and Truhlar, 2008) using the program NWChem (Valiev et al., 2010). While formally the selenite anion should lose an electron in vacuo, the finite basis set constrains the system to remain as $\mathrm{SeO}_{3}{ }^{2-}$. The parameterization of the intermolecular interactions within the model was performed by fitting to the experimental structure data of $\mathrm{CaSeO}_{3}$ (monocl.) and to the elastic constants of the same phase, which have been computed with the aid of WC-USP by applying the strain-stress relationship. WC-USP based elastic constants are compared to the constants predicted with the optimized force-field model in the Supplementary Information Table S1. A comparison of DFT based and experimental cell parameters is shown in Table S2. The fitting and the geometry optimization were performed with the General Utility Lattice Program (GULP) (Gale and Rohl, 2003). The parameters of the optimized forcefield model are given in Table S3. The entropies of the supercell within a single defect supercell and the entropies of $\mathrm{CaCO}_{3}$ and $\mathrm{CaSeO}_{3}$ (monocl.) were computed at $298.15 \mathrm{~K}$ from the phonon densities of states. These calculations included the calculation of the heat capacity from the phonon density of states at the optimized volume. No correction for thermal expansion was included as this is an insignificant contribution at $298.15 \mathrm{~K}$. The calculations were fully converged with respect to the k-point density within the Brillouin zone.

Given that it is not currently practical to extensively sample the configuration space of water molecules over the surface of calcite using DFT, further use of the force-field calculations can be made to assess the validity of the solvation contribution to the energetics of selenite incorporation. To do this, the COSMIC solvation model (Gale and Rohl, 2007) has been employed to provide information on the solvation free energies of the calcite surface, with and without selenite present. In order to do this, there are several key parameters that go into determining the solvent accessible surface, including the radii of the ions. In a recent work the same solvation model has been used to estimate the interfacial energy between calcite and water (Bruno et al., 2013). However, here the radii were taken from standard tabulations without checking whether they yield the correct thermodynamics for the component ions in solution. In the present work we have fitted the radii of $\mathrm{Ca}, \mathrm{C}, \mathrm{Se}$, and $\mathrm{O}$ against the free energies of hydration of $\mathrm{Ca}^{2+}$, $\mathrm{CO}_{3}{ }^{2-}$ and $\mathrm{SeO}_{3}{ }^{2-}$. Here the values adopted for $\mathrm{Ca}^{2+}(-1444 \mathrm{~kJ} / \mathrm{mol})$ (David et al., 2001) and $\mathrm{CO}_{3}{ }^{2-}(-1315$ $\mathrm{kJ} / \mathrm{mol}$ ) (Marcus, 1991) are taken from experiment, while in the case of $\mathrm{SeO}_{3}{ }^{2-}$ the only estimates of the free energy of hydration come from quantum mechanical calculations (Wicke and Meleshyn, 2010) and 
694 we have taken the upper bound $(-945 \mathrm{~kJ} / \mathrm{mol})$. The final solvation parameters are a water dielectric 695 constant of 78.4, a radius shift of $1.2 \AA$ during creation of the solvent accessible surface, which consists 696 of 110 points per atom, and a smoothing range of $0.2 \AA$. The fitted van der Waals radii for the elements 697 are 1.89, 1.32, 1.32 and $3.34 \AA$ for $\mathrm{Ca}, \mathrm{C}, \mathrm{O}$ and Se, respectively. All force-field calculations for surfaces 698 were run using 2-D periodic boundary conditions within the two region approach, in which the region 699 nearest the surface is fully relaxed while the underlying region is held fixed at the bulk geometry to 700 recreate the potential on the surface region. A thickness of 4 layers of calcite for each region was found 701 to be sufficient to yield converged surface energies. 
EXAFS data measured on the powder sample and in a polarization dependent experiment on a single crystal are shown in Figure 2 (circles). Absorption edge raw data are not shown, but it should be mentioned that none of the spectra showed any indication of reduction or oxidation of selenium during the coprecipitation reactions. The edge energy $\left(E_{0}\right)$ for the subtraction of the background is set to the first inflection point at the absorption edges, which is at $12.664 \mathrm{keV}$ for the powder EXAFS data and at $12.663 \mathrm{keV}$ for the single crystal data. The k-space EXAFS data in Figure 2a shows that the orientation of the polarization vector relative to the sample had a clear effect on the amplitude of the signal. For the "bpa" orientation (green) an increased amplitude of the EXAFS signal relative to the isotropic data (black) measured on the powder sample is especially obvious. This is expected because the data labeled "bpa" were measured with $\vec{\varepsilon}$ parallel to the [010] direction, which is in the plane of the carbonate ions. This already shows qualitatively that there must be a preferential orientation of the selenite molecule relative to the calcite structure, which is a clear indication for the structural incorporation of selenite into calcite. It is likely that this orientation is parallel to that of the carbonate ions. Quantitative interpretation of the EXAFS data is performed as described in the experimental section. All the spectra are modeled considering four shells of backscattering atoms.

The first shell $\left(\mathrm{O}-\mathrm{SeO}_{3}\right)$ contains the three oxygen atoms belonging to the $\mathrm{SeO}_{3}{ }^{2-}$ ion. The second shell (O$\mathrm{CO}_{3}$ ) is also comprised of three oxygen atoms. It is assumed that these oxygen neighbors belong to three different carbonate ions located above the pyramidal selenite ion. The next two shells (Ca1 and Ca2) consist of three calcium atoms each. In the original calcite structure all of these six calcium atoms have the same distance to the central carbon atom of the carbonate ion, but on substituting the flat carbonate ion by a pyramidal selenite ion they become split into two shells with clearly distinct bond distances. The results from the EXAFS data modeling are listed in Table 2. The amplitude reduction factor $\mathrm{S}_{0}{ }^{2}$ is $0.85 \pm 0.05$ for all datasets. It is adjusted to make the coordination number of the $\mathrm{O}-\mathrm{SeO}_{3}$ shell, $\mathrm{N}_{\text {iso }}\left(\mathrm{O}-\mathrm{SeO}_{3}\right)=3.0$. The bond distances obtained from modeling the isotropic data are in excellent agreement with those reported by Aurelio et al. (Aurelio et al., 2010). They concluded from their structural study of selenium(IV) substitution in calcite, that selenite is structurally incorporated into calcite, where it substitutes for a carbonate ion in the crystal structure. This is the most likely substitution mechanism from a crystal chemical perspective, and is in excellent agreement with our data as well. The coordination numbers we obtain from modeling the isotropic dataset are in even better agreement than the previous work with the value of three, expected for all shells for a substitution of carbonate for selenite. This is probably due to the fact that Aurelio et al. kept the Debye-Waller factors, which are strongly correlated with the coordination numbers, at a very low value of $0.002 \pm 0.001$ for all shells. The adjustment of the Debye Waller factors in this study, not only improves the agreement with the expected coordination numbers, but it also improves the quality of the fit. Considering the size of the selenite ion compared to a carbonate, we consider it likely that there is a certain degree of disorder in the structure surrounding the selenium atom, which is expressed in elevated Debye Waller factors. 
limited amount of selenium in their precipitates, the change of the unit cell volume is not well correlated with the selenite content of the crystals. A second important point regarding the neutron diffraction data is that there is no indication for the formation of a separate $\mathrm{CaSeO}_{3}$ phase. In the search for additional evidence for the structural incorporation of selenite in calcite we performed polarization dependent EXAFS experiments. Bond distances and Debye Waller factors derived from modeling the polarization dependent data are in good agreement with those obtained from the isotropic data. The quantification of the polarization effect in terms of $\mathrm{N}_{\text {eff }}$ values is listed in Table 2 and depicted in Figure 3 . The quantitative interpretation is limited by the uncertainty limits of the effective coordination numbers. For data measured in orientations "bpa" and "bpb" differences in effective coordination numbers are greater than the uncertainty limits for the first two shells. Data measured in orientation "bpk" have a worse signal to noise ratio than the other two datasets. This translates to uncertainties in the effective coordination numbers. Nevertheless, the effective coordination number measured for the first shell in the "bpk" orientation is significantly different from the one measured for orientation "bpa". The number of degrees of freedom, that are in principle available when trying to find a structural model that fits EXAFS bond distances and effective coordination numbers, is very high. Therefore it has been decided to make some assumptions in regards to the structural model in order to keep it as simple as possible. The selenite ion is placed at the position of a carbonate ion in the calcite structure, with the selenium atom on a threefold symmetry axis, parallel to the $c$ axis of the hexagonal calcite coordinate system. Atoms in one shell are only translated in planes perpendicular to the symmetry axis, or the planes are moved along the symmetry axis. Rotations of groups of atoms around the axis do not influence the result and are therefore not considered. Even though this might be more strictly constrained than necessary, this model is already able to reproduce all the effective coordination numbers within the uncertainty, while matching the bond distances determined from the polarization dependent data exactly. Effective coordination numbers obtained for the structural model (Neff_..._model), compared to the measured effective coordination numbers (Neff_..._exp) are displayed in Figure 3, along with effective coordination numbers as calculated for the structure obtained from WC-USP calculations (Neff_..._WC). The model, as well as the theoretical structure, matches the experimentally derived effective coordination numbers very well. A detailed description of the structure resulting from the quantitative interpretation of the polarization dependent EXAFS data and a comparison of this structure to theoretical results is given in the Supplementary Information.

A representation of the proposed best fit structure of the incorporated anion is displayed in Figure 4 . Indicated are the orientation of the calcite (104) plane and the directions of the polarization vectors corresponding to the three different orientations investigated. The same structure would, of course, be possible with the selenite pyramid pointing the other way around. Due to the $\cos ^{2}$ relation between $\theta$ and $\mathrm{N}_{\text {eff, }}$ the polarization dependent EXAFS data cannot be used to distinguish between these two orientations. It is interesting to note that the effective coordination numbers for orientation "bpk" are all close to three, the value of the real coordination numbers. This is because during the "bpk" measurements $\vec{\varepsilon}$ was parallel to the [46-1] direction. This vector comprises an angle of $57.1^{\circ}$ with the threefold symmetry axes, which is close to the "magic angle" for polarization dependent EXAFS measurements of $54.7^{\circ}$ (Schlegel et al., 1999). 
Based on the structural investigations presented here it is proposed that selenite is structurally incorporated into calcite upon coprecipitation under surface controlled growth conditions. In the calcite structure selenite substitutes a carbonate ion and forms a solid solution with the stoichiometry $\mathrm{Ca}\left(\mathrm{SeO}_{3}\right)_{X}\left(\mathrm{CO}_{3}\right)_{(1-\mathrm{x})}$, where $\mathrm{X}$ denotes the mole fraction of selenite in the solid. This observation is in excellent agreement with the study by Aurelio et al. (2010). In their study calcite is precipitated at very high initial supersaturations (SI(calcite) 5). Therefore, results by Aurelio et al. indicate that the same substitution mechanism is active, even if calcite is precipitated at much higher supersaturations.

\subsection{Thermodynamic interpretation of the experimental and theoretical results}

Partition coefficients are constant over a large range of selenite content in the solid or liquid phase. This relation can be seen as the linear dependence between $\mathrm{c}\left(\mathrm{SeO}_{3}{ }^{2-}\right) / \mathrm{c}\left(\mathrm{CO}_{3}{ }^{2-}\right)$ and $\mathrm{X}\left(\mathrm{CaSeO}_{3}\right) / \mathrm{X}(\mathrm{calcite})$ in Figure 5. From linear regression of the data in Figure $5(y$-intercept $=0)$ we obtain the apparent partition coefficient: $D_{\text {exp }}=0.02 \pm 0.01\left(R^{2}=0.99\right)$.

A constant partition coefficient over a large range of solid compositions suggests that it is possible to describe the system as an ideal solid solution (cf. equation (5b)). If we apply eqns. (5b), (7), and (12) to the apparent partition coefficient obtained from linear regression ( $D=0.02 \pm 0.01$ ), we can calculate an apparent solubility product of the virtual $\mathrm{CaSeO}_{3}$ endmember of $\log _{10}\left(\mathrm{~K}_{\mathrm{SP}}\left(\mathrm{CaSeO}_{3_{-} \text {exp }}\right)\right)=-6.7 \pm 1.0$, and a Gibbs free energy of formation of $-953 \pm 6 \mathrm{~kJ} / \mathrm{mol}$, which corresponds to an $\Delta \mathrm{G}^{\mathrm{E}}{ }_{\exp }$ of $2 \pm 2 \mathrm{~kJ} / \mathrm{mol}$ (Tables 3 and 4).

\subsubsection{Estimation of the thermodynamic stability of the monoclinic reference $\mathrm{CaSeO}_{3} \mathrm{compound}$}

The reaction enthalpy of the reaction $\mathrm{BaSeO}_{3}+\mathrm{CaCO}_{3}$ (aragonite) $\rightarrow \mathrm{CaSeO}_{3}+\mathrm{BaCO}_{3}$ (eqn. (17)) calculated by WC-USP is $-3 \mathrm{~kJ} / \mathrm{mol}$. This value, together with the free energies of formation of all the relevant phases (Table 3), yields $\mathrm{G}\left(\mathrm{CaSeO}_{3}\right.$, monocl. $)=-954 \mathrm{~kJ} / \mathrm{mol}$. The enthalpy of the reaction $\mathrm{SrSeO}_{3}+$ $\mathrm{CaCO}_{3}$ (aragonite) $\rightarrow \mathrm{CaSeO}_{3}+\mathrm{SrCO}_{3}$ (eqn. (18)) is $-11 \mathrm{~kJ} / \mathrm{mol}$. The corresponding free energy value of $\mathrm{CaSeO}_{3}$ is $-957 \mathrm{~kJ} / \mathrm{mol}$. The difference between these values of the free energy is assumed to characterize the lower limit of uncertainty in these calculations, as it doesn't include the uncertainty of the tabulated thermodynamic constants, which could easily add another $2 \mathrm{~kJ} / \mathrm{mol}$ to the estimated uncertainty. In subsequent calculations we adopt the average value $\mathrm{G}\left(\mathrm{CaSeO}_{3}\right.$, monocl. $)=-956 \pm 4$ $\mathrm{kJ} / \mathrm{mol}$. This value corresponds to a solubility product of $\log _{10}\left(\mathrm{~K}_{\mathrm{SP}}\left(\mathrm{CaSeO}_{3}\right.\right.$, monocl. $\left.)\right)=-7.06 \pm 0.70$. It is similar to the measured solubility product of $\mathrm{CaSeO}_{3} \cdot \mathrm{H}_{2} \mathrm{O}, \log _{10}\left(\mathrm{~K}_{\mathrm{SP}}\left(\mathrm{CaSeO}_{3} \cdot \mathrm{H}_{2} \mathrm{O}\right)\right)=-6.40 \pm 0.25$ (Olin et al., 2005), the phase that precipitates at elevated $\mathrm{Ca}^{2+}$ and $\mathrm{SeO}_{3}{ }^{2-}$ concentrations from aqueous solution at room temperature. This might indicate that the hydrate, $\mathrm{CaSeO}_{3} \cdot \mathrm{H}_{2} \mathrm{O}$, is a metastable phase that persists at standard conditions during the time frame of solubility experiments, while $\mathrm{CaSeO}_{3}$ (monocl.) is only observed in experiments at hydrothermal conditions (Wildner and Giester, 2007). Another possible explanation is that the stability of $\mathrm{CaSeO}_{3}$ (monocl.) is slightly overestimated. 
821 Using eqn. (9) and the calculated DFT enthalpies (Table S4) we obtain values for the excess enthalpy of 822 the virtual bulk $\mathrm{CaSeO}_{3}$ endmember, which are $41 \mathrm{~kJ} / \mathrm{mol}, 53 \mathrm{~kJ} / \mathrm{mol}$, and $48 \mathrm{~kJ} / \mathrm{mol}$ from WC-USP, PBE823 PAW, and PBE-USP calculations, respectively. Our force-field calculations give a much smaller value of 824 the excess enthalpy $(17 \mathrm{~kJ} / \mathrm{mol})$ and an even smaller value of excess Helmholtz free energy $(13 \mathrm{~kJ} / \mathrm{mol})$. 825 We believe that the force-field model significantly underestimates the excess enthalpy, however, we 826 take the difference between the last two values as the best estimate of the effect of the vibrational free energy. According to our force-field model the vibrational free energy decreases the total excess Gibbs free energy of the virtual bulk $\mathrm{CaSeO} 3$ endmember by $4 \mathrm{~kJ} / \mathrm{mol}$. Thus our best estimate of the excess Gibbs free energy of the virtual bulk $\mathrm{CaSeO}_{3}$ endmember is $43 \pm 6 \mathrm{~kJ} / \mathrm{mol}$ based on correcting the average DFT excess enthalpy. We conclude that the effect of the vibrational free energy makes a relatively small contribution to the excess Gibbs free energy of the virtual endmember. In subsequent calculations the vibrational contributions to the excess functions will therefore be ignored. The absolute standard Gibbs free energy of the virtual bulk $\mathrm{CaSeO}_{3}$ endmember can be calculated by adding the excess effect of $43 \mathrm{~kJ} / \mathrm{mol}$ to the standard Gibbs free energy of $\mathrm{CaSeO}_{3}$ (monocl.). Thus we obtain a value of $\mathrm{G}^{0}\left(\mathrm{CaSeO}_{3}\right.$ bulk $)=-912 \pm 10 \mathrm{~kJ} / \mathrm{mol}$, corresponding to $\log _{10}\left(\mathrm{~K}_{\mathrm{SP}}\left(\mathrm{CaSeO}_{3 \_ \text {bulk }}\right)\right)=0.5 \pm 1.7$.

The computed $\mathrm{G}^{0}\left(\mathrm{CaSeO}_{3}\right.$ bulk $)$ allows straightforward estimation of the maximum concentration of $\mathrm{CaSeO}_{3}$ in calcite that can be in equilibrium with aqueous solution. In this estimation we assume that the equilibrium ion activity product $\operatorname{IAP}\left(\mathrm{CaSeO}_{3}\right)$ (cf. eqn. (3a)) is limited by the solubility product of

$\mathrm{G}^{0}\left(\mathrm{CaSeO}_{3}\right.$ virtual $)+\mathrm{RT} \ln \left(\mathrm{X}_{\max }\left(\mathrm{CaSeO}_{3}\right)\right)=\mathrm{G}^{0}\left(\mathrm{CaSeO}_{3} * \mathrm{H}_{2} \mathrm{O}\right)-\mathrm{G}^{0}\left(\mathrm{H}_{2} \mathrm{O}\right)$

841 Using the values from Table 3 we obtain $X_{\max }=10^{-7}$. This value is six orders of a magnitude lower than the 842 highest concentration measured in MFR experiments (ca. 7\%). A more general way to see the striking 843 difference between the experiment and the bulk solid solution theory is to compare the apparent and 844 the theoretically predicted solubility constants of the $\mathrm{CaSeO}_{3}$ endmember $\left(\log _{10} \mathrm{~K}=-6.7\right.$ and $\log _{10} \mathrm{~K}=0.5$, 845 respectively), the corresponding partition coefficients $\left(0.02\right.$ and $10^{-9}$, respectively), and $\Delta G^{\mathrm{E}}$ values (2 $846 \mathrm{~kJ} / \mathrm{mol}$ and $43 \mathrm{~kJ} / \mathrm{mol}$, respectively).

847 The small value of the maximum mole fraction of $\mathrm{SeO}_{3}{ }^{2-}$ in calcite is the consequence of the predicted 848 large excess Gibbs free energy of the virtual endmember. Apparently, this value reflects the large stress 849 that the $\mathrm{SeO}_{3}{ }^{2-}$ unit experiences in the calcite structure. This stress can be related to the geometry misfit 850 between the planar $\mathrm{CO}_{3}{ }^{2-}$ unit and the larger $\mathrm{SeO}_{3}{ }^{2-}$ pyramid.

851 4.2.3 The surface solid solution concept and the thermodynamic entrapment model

852 Obviously a disagreement of several orders of magnitude between the experimental and computational 853 results for $\mathrm{SeO}_{3}{ }^{2-}$ incorporation into bulk calcite highlighted above requires an explanation. Although the 854 DFT calculated bulk structures are in close agreement with the EXAFS results, the predicted partition 855 coefficient and $\Delta G^{E}$ value differ greatly from those measured experimentally. 
Our first assumption was that the high partition coefficient observed in the experiments could be explained within the kinetic model of Shtukenberg et al. (2006). However, our model calculations showed that if the theoretical partition coefficient, $10^{-9}$, is assumed to reflect equilibrium partitioning and the partition coefficient is assumed to approach unity for infinitely high supersaturation, the experimentally observed partition coefficient of 0.02 would be expected at supersaturations exceeding those in MFR experiments by 7 orders of magnitude.

A solution to the problem can be found if the assumption is made that the experimental concentration of $\mathrm{SeO}_{3}{ }^{2-}$ in calcite is controlled not by the thermodynamic properties of the bulk solid solution, but by the properties of the surface layer of calcite, which provide favorable conditions for the $\mathrm{SeO}_{3}{ }^{2-}$ adsorption. It appears possible that this Se-enriched surface layer can be continuously entrapped and renewed if the driving force for the calcite precipitation is sufficiently high.

Cowan et al. (1990) suggested that the selenite adsorption on calcite occurs as an ion-exchange process. This assumption was later confirmed by X-ray standing wave measurements (Cheng et al., 1997). The results of these studies imply that the selenite incorporation into the calcite surface monolayer is more favorable than the incorporation into the bulk of calcite. Conceptually, ion-exchange at the surface is equivalent to the formation of a solid solution within the surface monolayer. Following this line of thought, we can assume that the partition coefficient measured in MFR experiments reflects the thermodynamics of selenite incorporation into the calcite surface monolayer. $\mathrm{SeO}_{3}{ }^{2-}$ incorporation into such a surface solid solution should be determined by the difference in the free energies of the surface endmembers of $\mathrm{CaCO}_{3}$ and $\mathrm{CaSeO}_{3}$ composition. The latter difference can in turn be defined relative to the free energy difference between calcite and monoclinic $\mathrm{CaSeO}_{3}$ via the $\Delta \mathrm{G}_{\text {surface }}^{\mathrm{E}}$ parameter, as discussed in Section 2.2. Applying eqn. (13) to the experimentally derived partition coefficient, we obtain, $\Delta \mathrm{G}_{\text {exp }}^{\mathrm{E}}=\Delta \mathrm{G}_{\text {surface }}^{\mathrm{E}}=2 \pm 2 \mathrm{~kJ} / \mathrm{mol}$.

The surface solid solution entrapment concept is further developed in Figure 6. In coprecipitation experiments, calcite grows with a composition that is determined by the stationary activities of $\mathrm{CO}_{3}{ }^{2-}$ and $\mathrm{SeO}_{3}{ }^{2-}$ in the reactor, and by the thermodynamic properties of the surface solid solution (reaction 1 in Figure 6). As discussed above, the precipitation from a supersaturated solution can be fitted into the equilibrium thermodynamic concept under the assumption that the most highly supersaturated solid solution composition precipitates (Prieto, 2009). The observed high selenite content in MFR experiments can be explained under the assumption that upon crystal growth the surface solid solution is buried under newly formed mineral layers, without being able to change its composition. In other words, the surface solid solution is entrapped (reaction 2 in Figure 6). It likely takes a couple of add layers ( $>4$, (Fenter and Sturchio, 2012)) until a bulk-like situation is achieved. Once entrapped in the bulk, the selenite ion and the surrounding calcite host experiences a considerable strain, as reflected by the thermodynamic parameters derived from bulk DFT calculations $\left(\Delta \mathrm{G}_{\text {bulk }}^{\mathrm{E}}=43 \pm 6 \mathrm{~kJ} / \mathrm{mol}\right.$ ). The amount of energy needed to transform the surface solid solution into a bulk solid solution (indicated in Figure 6 as $\Delta G_{\text {entrapment }}$ ) can be approximated as:

$\Delta \mathrm{G}_{\text {entrapment }}=X \cdot\left(\Delta \mathrm{G}_{\text {bulk }}^{\mathrm{E}}-\Delta \mathrm{G}_{\text {surface }}^{\mathrm{E}}\right)=\mathrm{X} \cdot(41 \pm 8) \mathrm{kJ} / \mathrm{mol}$.

For the lattice layer to be entrapped continuously, this energy needs to be balanced by the 
supersaturation. The entrapment model of Watson (2004) includes the possibility of diffusion of the entrapped ions out of a near surface region. If such a process would take place, eqn. (25) would not be correct. However, in section 4.3 we show that the composition of the surface solid solution formed in the adsorption experiments at equilibrium conditions appears to be consistent with the composition of the solid phase formed via coprecipitation. Therefore we consider the backward diffusion process to be insignificant for selenite coprecipitation with calcite at room temperature. The negligible reverse diffusion is likely to be related to the large size of the $\mathrm{SeO}_{3}{ }^{2-}$ ion.

High $\mathrm{SeO}_{3}{ }^{2-}$ concentrations in bulk calcite resulting from entrapment reflect non-equilibrium. It is interesting to speculate on the fate of Se-calcites at close-to-equilibrium conditions. It is likely that the surface layer might easily change its composition and be equilibrated with an aqueous solution. However, ions in the non-equilibrium bulk cannot exchange with ions in solution except through the surface. The surface layer could thus effectively passivate the solid against the reverse reaction. Whether, over geological periods of time, calcite recrystallization and release of $\mathrm{SeO}_{3}{ }^{2-}$ back into solution (reaction 3 in Figure 6) or a metastable preservation of the non-equilibrium bulk is to be expected, remains an open question.

In order to corroborate this thermodynamic entrapment concept we attempt to derive the $\Delta \mathrm{G}_{\text {surface }}^{\mathrm{E}}$ values required to quantify surface incorporation according to eqn. (13) from DFT calculations. Based on equations (13) to (18) and the various surface DFT calculations (see Table S4), we obtain a range of $\Delta \mathrm{G}^{\mathrm{E}}{ }_{\text {surface }}$ values. It is interesting to note that calcite-vacuum interface calculations consistently predict a relative stabilization $\left(\Delta \mathrm{G}_{\text {surface }}^{\mathrm{E}}<0\right)$ of the calcite surface upon substitution of surface $\mathrm{CO}_{3}{ }^{2-}$ for $\mathrm{SeO}_{3}{ }^{2-}$. The corresponding partition coefficients are in the range from 0.6 to 15 and are higher than the experimental value, 0.02 (Table 4.).

To simulate the influence of interfacial water on the selenite surface substitution, we have performed DFT calculations including 31 water molecules per supercell above one side of the calcite slab. The water molecules are arranged in three layers as described in the section 3.3.2. The predicted structuring of the interfacial water is in good agreement with previous experimental and computational results (Heberling et al., 2011; Raiteri et al., 2010; Fenter et al., 2013). The specific effect we were after is the difference in the total energies of the supercells with and without a substitutional defect of $\mathrm{SeO}_{3}{ }^{2-}$ placed in the surface layer. We are aware that a model with only three layers of water in a single configuration represents a crude approximation to dynamical solvation effects. Nevertheless, the calculations with the interfacial water reveal some interesting effects. The $\Delta \mathrm{G}^{\mathrm{E}}{ }_{\text {surface }}$ values obtained for selenite substitution at the calcite-water interface are drastically increased in the presence of water, compared to the calcitevacuum interface calculations (Table 4). We observe a periodicity in the water structure, which results in (at least) two non-equivalent sites for the selenite substitution (labeled Se1 and Se2 in Table 4). The

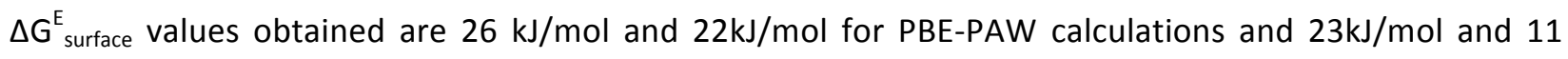
$\mathrm{kJ} / \mathrm{mol}$ for PBE+D-USP calculations for Se1 and Se2, respectively. The Se1 configuration obviously represents a metastable local minimum in the structure optimization, and so the more stable Se2 configuration is considered the relevant structure for comparison with experimental data. The average $\Delta \mathrm{G}_{\text {surface }}^{\mathrm{E}}$ value for Se2, $17 \mathrm{~kJ} / \mathrm{mol}$, is in relatively good agreement with the experimental value $\Delta \mathrm{G}_{\exp }^{\mathrm{E}}=2$ $\pm 2 \mathrm{~kJ} / \mathrm{mol}$ considering the approximate nature of the model. 
Due to computational time limitations, we did not explore the convergence of the results with respect to the concentration of selenite in calcite (the size of the supercell) and we have ignored entropic effects. The limited size of the $2 \times 2$ supercell also does not allow us to exclude the effect of defect-image interactions. Indeed, due to periodic boundary conditions the $\mathrm{SeO}_{3}{ }^{2-}$ defect will experience the presence of the defect images located in the neighboring periodically repeated images of the supercell. An estimate of the possible error due to defect-image interactions can be obtained from comparing the bulk DFT calculations using different unit cell shapes. Accordingly we take the standard deviation of $\Delta \mathrm{G}_{\text {bulk }}^{\mathrm{E}}$ values, $6 \mathrm{~kJ} / \mathrm{mol}$, as an estimate of this uncertainty. A similar uncertainty is expected in the calculations for the supercells including a vacuum- or water-interface. The model of three layers of water certainly represents a crude approximation to the full dynamical picture of solvation. It is likely that in reality $\Delta \mathrm{G}_{\text {surface }}^{\mathrm{E}}$ is determined by the averaged effect of many different configurations of water. Our calculations probe just two slightly different configurations of water, Se1 and Se2. The differences between $\Delta \mathrm{G}^{\mathrm{E}}$ surface values obtained for the different $\mathrm{SeO}_{3}{ }^{2-}$ substitution sites in the calcite-water interface calculations of 4 $12 \mathrm{~kJ} / \mathrm{mol}$ plus the uncertainty due to the defect-image interactions of $\mathrm{ca} .6 \mathrm{~kJ} / \mathrm{mol}$ is used here to associate the likely error in the range of $10-18 \mathrm{~kJ} / \mathrm{mol}$ with the estimated $\Delta \mathrm{G}^{\mathrm{E}}$ surface values.

Despite the limitations of surface calculations discussed above, the $\Delta \mathrm{G}_{\text {surface }}^{\mathrm{E}}$ values derived from DFT closely approach the experimentally derived value, and confirm the assumption that the incorporation of $\mathrm{SeO}_{3}{ }^{2-}$ into the calcite surface is energetically more favorable than the incorporation of $\mathrm{SeO}_{3}{ }^{2-}$ into the bulk calcite structure. It appears that the specific orientation of the $\mathrm{SeO}_{3}{ }^{2-}$ unit, with the Se atom pointing away from the surface, allows a reduction in the stress that exists in the bulk structure. This structural arrangement, obtained in all surface substitution calculations, is in qualitative agreement with the structure obtained by Cheng et al. from X-ray standing wave measurements (Cheng et al., 1997).

Surface hydration stabilizes the pristine calcite (104) cleavage plane by reducing the surface energy. Therefore it makes the substitution reaction energetically less favorable by $\sim 30 \mathrm{~kJ} / \mathrm{mol}$. In other words, the presence of interfacial selenite weakens the surface hydration. This effect is a consequence of the less exothermic free energy of solvation of the selenite anion relative to the carbonate anion. Thus it appears that the presence of the selenite defect reduces the stabilization of the calcite-water interface by decreasing the interfacial free energy.

Using the force-field approach with the COSMIC continuum solvation model this effect can be confirmed, in that hydration increases the $\Delta \mathrm{G}_{\text {surface }}^{\mathrm{E}}$ value for surface incorporation of selenite by $50 \mathrm{~kJ} / \mathrm{mol}$.

Although there is a quantitative discrepancy between the DFT and the force-field result, the key result is the validation of the trend (i.e. the effect of hydration of the surfaces is to increase $\Delta \mathrm{G}_{\text {surface }}^{\mathrm{E}}$ by $23 \mathrm{~kJ} / \mathrm{mol}$, $37 \mathrm{~kJ} / \mathrm{mol}$, and $50 \mathrm{~kJ} / \mathrm{mol}$, for PBE(+D)-USP, PBE-PAW, and Force-Field, respectively).

One significant result that emerges from the continuum solvation calculations is that the calcite (104) surface energy on hydration is reduced from $0.71 \mathrm{Jm}^{-2}$ to $0.28 \mathrm{Jm}^{-2}$. This change of $-0.43 \mathrm{Jm}^{-2}$ is an order of magnitude larger than the equivalent value found by Bruno et al. (2013) using the same approach. In their work Bruno et al. claim to have examined the sensitivity to the choice of solvation parameters to demonstrate that the answers they obtain are not especially influenced by these. However, for $\mathrm{Ca}^{2+}$ they only examined radii in the range of 2.75 to $2.90 \AA$, compared to a best fit value of $1.89 \AA$ used here. 
974 (Note that the exact radius that should be used to reproduce our results is $1.8885 \AA$.) This means that 975 their free energies of hydration for $\mathrm{Ca}^{2+}$ were underestimated by between 453 and $504 \mathrm{~kJ} / \mathrm{mol}$, leading 976 to strongly reduced solvation of the calcite surface.

\subsection{Adsorption}

979 The entrapment concept implies that equilibrium incorporation into the bulk crystal is practically impossible, while the spontaneous structural incorporation of $\mathrm{SeO}_{3}{ }^{2-}$ into calcite at equilibrium conditions can occur within the surface monolayer (Figure 6, middle). To test this hypothesis we compare the partition coefficients measured in MFR coprecipitation experiments to the partition coefficients that describe the surface incorporation (ion-exchange) measured in selenite adsorption experiments at equilibrium conditions $\left(\mathrm{SI}(\right.$ calcite $)=0$ ). Our experiments (Figure 7 ) are consistent with $\mathrm{K}_{\mathrm{D}}$ $\approx 0.002 \mathrm{~L} / \mathrm{g}$ at $\mathrm{pH}<9$.

Regarding the total adsorbed amount and the $\mathrm{pH}$ dependence of adsorption, our results are in good agreement with previous experiments by Cowan et al. (1990). Within the proposed entrapment concept the adsorption $K_{D}$ can be translated into a partition coefficient related to a surface monolayer solid solution. The data for adsorption experiments in the $\mathrm{pH}$ range from 7.5 to 8.2 are plotted as orange circles in Figure 5. This range covers the $\mathrm{pH}$ range of MFR experiments (except for the experiment MFRSe EXAFS). The data in Figure 5 at low concentrations are taken from the adsorption experiments performed in the present study, while the data at intermediate concentrations are calculated from the adsorption isotherms by Cowan et al. (1990). The data point at the highest Se concentration is calculated from the surface coverage and the solution composition reported by Cheng et al. (1997). The agreement between the $D$ values related to adsorption and coprecipitation is remarkable. It strongly supports the concept that coprecipitation is a series of surface ion-exchange reactions and subsequent entrapment events. The observed similarity of the $D$ values supports the hypothesis that surface diffusion plays a negligible role during selenite coprecipitation. Furthermore, the agreement between partition coefficients obtained in equilibrium adsorption and coprecipitation experiments at supersaturated conditions justifies the approach to apply equilibrium thermodynamic expressions to coprecipitation experiments at supersaturated conditions.

The fact that the surface adsorption strongly decreases at high $\mathrm{pH}$, and the similarity between surface adsorption and coprecipitation, suggests that a similar $\mathrm{pH}$ dependence should be expected in coprecipitation experiments. However, the MFR experiment conducted to synthesize the non-radioactive Se-calcite, MFR-Se EXAFS, showed significant selenite incorporation at $\mathrm{pH} 10.33$. The amount of selenite incorporation was, however, not quantified in this experiment. Further MFR experiments will be necessary to investigate selenite coprecipitation with calcite as a function of $\mathrm{pH}$.

\subsection{Entrapment energy and growth inhibition}

For a crystal to grow a supersaturated contact solution is required. Our entrapment concept suggests 
1012

1013

1014

1015

1016

1017

1018

1019

1020

1021

1022

1023

1024

1025

1026

1027

1028

1029

1030

1031

1032

1033

1034

1035

1036

1037

1038

1039

1040

1041

1042

1043

1044

1045

1046

1047

1048

1049

energy, which is required for transforming the surface solution into the bulk solid solution. This energy is indicated as $\Delta G_{\text {entrapment }}$ in Figure 6. This driving force for solid solution growth is only sufficient if the aqueous solution is supersaturated with respect to the bulk solid solution. The composition of the bulk solid solution, for which the supersaturation condition has to be fulfilled, is determined by the thermodynamics of the surface solid solution.

According to Prieto (2009), the stoichiometric supersaturation of an aqueous solution with respect to a solid solution is defined as;

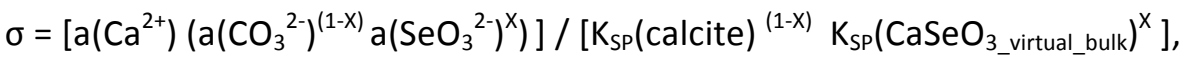

where $X$ is the mole fraction of $\mathrm{CaSeO}_{3}$ in the solid solution. It can be calculated on the basis of the experimental value, $\Delta G_{\text {surface }}^{\mathrm{E}}=2 \pm 2 \mathrm{~kJ} / \mathrm{mol}$, and eqns. (13) and (2). Eqn. 26 implies that the solid solution with the composition $\mathrm{X}$ can grow only when $\sigma>1$.

The above concept provides a consistent explanation of our aragonite recrystallization experiments in the presence and absence of selenite. In these experiments the maximum supersaturation with respect to calcite is given by the solubility difference between aragonite and calcite, and is intrinsically very low $(\mathrm{SI}$ (calcite) $=0.14)$. The $\mathrm{SeO}_{3}{ }^{2-}$ concentration in the selenite containing experiment is chosen to be relatively high: $10^{-4} \mathrm{~mol} / \mathrm{L}$. Based on the experimentally measured partition coefficient, at these conditions, the surface solid solution is predicted to contain $3 \%$ (mol) $\mathrm{CaSeO}_{3}$. In these calculations we assume that the aqueous speciation is controlled by the equilibrium with aragonite and atmospheric $\mathrm{CO}_{2}$. Consequently, the aqueous solution is supersaturated with respect to pure calcite, but is undersaturated with respect to the bulk calcite- $\mathrm{CaSeO}_{3}$ solid solution ( $\sigma=0.79$, right scheme in Figure 6 ).

Figure 8 illustrates our experimental results. These results show that in the selenite-free system (blue diamonds) aragonite dissolves over the experimental period of 420 days in favor of precipitation of the thermodynamically more stable calcite. In the selenite containing system (red squares) the formation of calcite is inhibited. In this system pure calcite cannot form, as all calcite surfaces would contain $3 \%$ (mol) $\mathrm{CaSeO}_{3}$, and the driving force is not high enough to entrap such a solid solution.

The observed inhibition could also be explained under the assumption that protruding step edges at the calcite surface are blocked by the impurities and are only able to proceed if the impurities are released back into the solution. It seems very likely that such a process would be extremely slow. At this stage we can only speculate on the exact mechanism of inhibition. Nevertheless, the absence of growth in the aragonite to calcite recrystallization experiment in the presence of $\mathrm{Se}$ (IV) is a strong experimental confirmation of the low stability of the virtual bulk $\mathrm{CaSeO}_{3}$ endmember, because the high $\Delta \mathrm{G}^{\mathrm{E}}$ bulk value is required to explain the undersaturation with respect to the bulk solid solution.

It should be mentioned that the aragonite used in the recrystallization experiments initially contains about $3 \%$ of vaterite. Due to the lower stability of vaterite compared to aragonite this leads to an initial period where $\mathrm{SI}$ (calcite) $=0.6$ and the bulk solid solution is supersaturated $(\sigma=2.63$ at an expected mole fraction of: $X=2 \%(m o l))$. Accordingly, solid solution growth is expected for an initial period until all vaterite is consumed. Indeed, the increase in the calcite fraction during the 420 day reaction period is not zero, but just enough (2.9\%) to account for the initial presence of vaterite. 
1052 Application of the stoichiometric supersaturation function requires a homogeneous solid solution and 1053 aqueous solution composition with fixed mole fractions of calcite and $\mathrm{CaSeO}_{3}$. In aragonite to calcite 1054 1055 recrystallization experiments this only holds as long as growth is inhibited and the selenite concentration does not decrease due to coprecipitation. However, this condition is perfectly fulfilled in steady state MFR experiments. Therefore stoichiometric supersaturation with respect to the bulk calcite- $\mathrm{CaSeO}_{3}$ solid solution is considered a likely candidate for the driving force for solid solution growth in MFR experiments. MFR growth rates in $\mathrm{nmol} /\left(\mathrm{m}^{2} \mathrm{~s}\right)$ as a function of stoichiometric solid solution supersaturation (in analogy to SI we use $\log _{10}(\sigma)$ ) are depicted in Figure 9.

Steady state supersaturation in MFR experiments is generally lower than the supersaturation in recently published AFM calcite growth experiments in the presence of selenite (Renard et al., 2013) (blue diamonds in Figure 9). This may give us some confidence that spiral growth, which is the dominant growth mechanism in AFM experiments, or layer growth at pre-existing steps are the dominant growth mechanisms in MFR experiments. In regard to the comparison of AFM and MFR growth rates, it is important to mention that a step density of $0.4 \mu \mathrm{m}^{-1}$ has been arbitrarily chosen in order to transform AFM step velocities in $\mathrm{nm} / \mathrm{s}$ to macroscopic growth rates in $\mathrm{nmol} /\left(\mathrm{m}^{2} \mathrm{~s}\right)$. According to AFM images (Renard et al., 2013) the average step density on the slopes of growth hillocks is about $10 \mu \mathrm{m}^{-1}$.

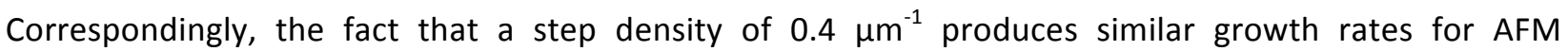
experiments as observed in MFR experiments, indicates that growth-hillocks must be relatively loosely 1071 spread over the surfaces of the calcite seed crystals in MFR experiments and it is likely that only about $4 \%$ of their surface is covered by growth spirals.

1072 The correlation between MFR growth rates in the presence of $\mathrm{Se}(\mathrm{IV})$ and $\log _{10}(\sigma)$ is weak. Nevertheless, 1073 comparison between MFR growth rates in the presence and absence of selenite (red squares and violet triangles in Figure 9, respectively) indicates a significant inhibiting effect of selenite on calcite growth even at trace concentrations (i.e. growth of pure calcite is faster at lower supersaturation compared to the selenite containing experiments). The use of $\sigma$ as characteristic supersaturation parameter considers 1077 the influence of selenite entrapment on the supersaturation. Comparison of the growth rates shows, 1078 however, that the growth inhibiting effect is underestimated by the consideration of $\sigma$.

1079 Considering the large effect selenite has on the morphology of growth features (Renard et al., 2013) or 1080 the changes in anion / cation ratio that are induced by adding selenite to the system, which are known to 1081 have a strong influence on growth rates (Stack and Grantham, 2010), it is not surprising that the correlation with the supersaturation is insufficient to describe the inhibition effect of selenite on the 1083 calcite growth rate, even if we consider the effect of selenite entrapment on the supersaturation. 


\section{Summary and Conclusions}

1086 According to EXAFS investigations selenite is structurally incorporated into calcite upon coprecipitation

1087

1088

1089

1090

1091

1092

1093

1094

1095

1096

1097

1098

1099

1100

1101

1102

1103

1104

1105

1106

1107

1108

1109

1110

1111

1112

1113

1114

1115

1116

1117

1118

1119

1120

1121

1122 at low supersaturation and slow growth rates. Upon coprecipitation a $\mathrm{Ca}\left(\mathrm{SeO}_{3}\right)_{x}\left(\mathrm{CO}_{3}\right)_{(1-\mathrm{x})}$ solid solution is formed. The structural environment of selenite in calcite according to EXAFS is in good agreement with the corresponding structures derived from DFT calculations and with previous studies (Aurelio et al., 2010).

From Mixed Flow Reactor experiments we derive an apparent partition coefficient for the selenite incorporation, $\mathrm{D}=0.02 \pm 0.01$, which corresponds to a solubility of a virtual $\mathrm{CaSeO}_{3}$ endmember of: $\log _{10}\left(\mathrm{~K}_{\mathrm{SP}}\left(\mathrm{CaSeO}_{3_{-} \mathrm{exp}}\right)\right)=-6.7 \pm 1.0$.

To corroborate this result, density functional theory calculations are used to predict the thermodynamics of mixing in the diluted solid solution of $\mathrm{CaSeO}_{3}$ in $\mathrm{CaCO}_{3}$. The method is seen as a generalization of the previously introduced Single Defect Method (Sluiter and Kawazoe, 2002; Vinograd et al., 2013) to a nonisostructural solid solution. The application of SDM provides the possibility to compute the standard Gibbs free energy of a virtual endmember, which by definition makes an ideal solid solution with the host phase. In contrast to the experiment, our DFT result suggests a much lower stability of the virtual bulk endmember, $\log _{10}\left(\mathrm{~K}_{\mathrm{SP}}\left(\mathrm{CaSeO}_{3}\right.\right.$ bulk $\left.)\right)=0.5 \pm 1.7$. This low stability suggests a maximum concentration of $\mathrm{SeO}_{3}{ }^{2-}$ in calcite of $\mathrm{X}_{\max }=10^{-7}$ and a partition coefficient of $\mathrm{D}=10^{-9}$. This shows that equilibrium incorporation of selenite into calcite is practically impossible.

To resolve the discrepancy between experiment and bulk thermodynamics, a surface entrapment model is proposed. The concept is based on the idea that substitution of carbonate by selenite in the calcite surface monolayer is energetically much less unfavorable compared to incorporation into the bulk crystal structure. The surface layer of calcite is therefore treated as a two-dimensional solid solution phase.

By treating the present batch type adsorption experiments of this study and earlier results on seleniteadsorption (Cheng et al., 1997; Cowan et al., 1990) in a pH range between 7.5 and 8.2 as the thermodynamic equilibrium between the aqueous and the surface solid solutions, it is shown that the adsorption data can be described by the same partition coefficient as the results of the selenite uptake via coprecipitation in an equivalent $\mathrm{pH}$ range. The adsorption experiments thus differ from the analogous coprecipitation experiments only in the degree of supersaturation, which may or may not be sufficient to maintain the continuous entrapment. In the close to equilibrium case the incorporation process stops when the original surface is equilibrated, while in the latter case, continuous growth and entrapment are expected. Aragonite recrystallization experiments confirm that continuous growth of the solid solution is only possible if the aqueous solution is supersaturated with respect to the bulk calcite- $\mathrm{CaSeO}_{3}$ solid solution, i.e. if the driving force is high enough to accomplish entrapment. These observations strongly support the central argument of the proposed entrapment concept, that there is a relatively large energetic difference between the surface and the bulk calcite- $\mathrm{CaSeO}_{3}$ solid solutions. It can be quantified by the entrapment energy, $\Delta G_{\text {entrapment }}=X \cdot(41 \pm 8) \mathrm{kJ} / \mathrm{mol}$. This difference in the Gibbs free energies of the endmembers of this solid solution and consequently the relative ease of the $\mathrm{SeO}_{3}{ }^{2-} / \mathrm{CO}_{3}{ }^{2-}$ substitution within the surface layer is confirmed with the SDM. 
1123 The practical consequence of the entrapment model for the interaction between aqueous selenite and 1124 calcite is that in equilibrium solutions interactions between selenite and calcite are restricted to the 1125 calcite surface monolayer. Thus, at near-equilibrium conditions calcite has only a limited potential to 1126 immobilize $\mathrm{SeO}_{3}{ }^{2-}$. However, depending on the system in consideration the retention can still be 1127 significant. Structural incorporation into bulk calcite only occurs if the aqueous solution is supersaturated 1128 with respect to the bulk calcite- $\mathrm{CaSeO}_{3}$ solid solution. In such a case selenite coprecipitates with calcite 1129 with the partition coefficient of $\mathrm{D}=0.02 \pm 0.01$. As a consequence, high $\mathrm{SeO}_{3}{ }^{2-}$ concentrations in bulk 1130 calcite reflect non-equilibrium. So far we can only speculate on the long-term behavior of Se-calcites at 1131 close-to-equilibrium conditions. It is likely that the surface layer can easily change its composition and be 1132 equilibrated with an aqueous solution. However, ions in the non-equilibrium bulk are not able to 1133 exchange with ions in solution except through the surface. The surface layer could thus effectively 1134 passivate the solid against recrystallization and release of $\mathrm{SeO}_{3}{ }^{2-}$ into solution.

1135 The model proposed here to describe selenite coprecipitation with calcite is not necessarily restricted to 1136 this system only. It might also apply to other pairs of host mineral and incorporated impurity. This will 1137 especially be true where the impurity ions experience a large stress upon incorporation into the bulk of 1138 the host mineral, while they are relatively well structurally compatible with the host mineral surface. 1139 Most obvious candidates for such systems are anionic substitutions where anions of the host mineral are 1140 substituted by complex anions that differ in size and geometry, like the case considered in this study. 1141 Similar effects might govern the incorporation of complex cations (e.g. actinyl cations) into host minerals 1142 of monatomic cations. Even simple cationic substitutions, particularly those characterized by large size 1143 mismatch between the host and the impurity cation, could to some extent be influenced by different 1144 thermodynamic properties of the surface and bulk solid solutions. 


\section{Acknowledgements}

1147 The authors would like to thank Eva Soballa and Dr. Dieter Schild for SEM and XPS analyses of calcite and 1148 aragonite samples. Tanja Kisely is acknowledged for performing BET analyses of the crystal powders.

1149 The authors gratefully acknowledge funding from the German Federal Ministry for Education and 1150 Research (BMBF) and the German Research Foundation (DFG) through the collaborative Project (CP) 1151 RECAWA within the research and development program "Geotechnologien", from DFG (grant VI 196/2-1) 1152 by the German Federal Ministry of Economics and Technology (BMWi) under grant agreement number 115302 E 10800 (CP-VESPA), and from the German Federal Ministry for Education and Research (BMBF) 1154 through the grant 02NUK019E (CP-IMMORAD). Further we gratefully acknowledge funding by the 1155 European Union's European Atomic Energy Community's (Euratom) Seventh Framework Program FP71156 Fission-2010 under grant agreement number 269688 (CP-SKIN). JDG thanks the Australian Research 1157 Council for funding under the Discovery Program and NCl/iVEC for the provision of computing resources.

1158 VLV acknowledges the provision of computational resources from the Jülich Supercomputing Center and 1159 at the Centre for Scientific Computing at the University of Frankfurt. 
Aquilano, D., Calleri, M., Natoli, E., Rubbo, M., Sgualdino, G., 2000. The $\{104\}$ cleavage rhombohedron of calcite: theoretical equilibrium properties. Materials Chemistry and Physics 66, 159-163. Astilleros, J.M., Pina, C.M., Fernandez-Diaz, L., Putnis, A., 2003. Supersaturation functions in binary solid solution-aqueous solution systems. Geochimica et Cosmochimica Acta 67, 1601-1608. Aurelio, G., Fernandez-Martinez, A., Cuello, G.J., Roman-Ross, G., Alliot, I., Charlet, L., 2010. Structural study of selenium(IV) substitutions in calcite. Chemical Geology 270, 249-256.

Blanchard, D.L., Baer, D.R., 1992. The Interactions of Co, Mn and Water with Calcite Surfaces. Surface Science 276, 27-39. Nucleation Mechanisms. Crystal Growth \& Design 13, 1170-1179.

Carroll, S.A., Bruno, J., Petit, J.C., Dran, J.C., 1992. Interactions of U(VI), Nd, and Th(IV) at the CalciteSolution Interface. Radiochimica Acta 58-9, 245-252.

Cheng, L.W., Lyman, P.F., Sturchio, N.C., Bedzyk, M.J., 1997. X-ray standing wave investigation of the surface structure of selenite anions adsorbed on calcite. Surface Science 382, L690-L695. Clark, S.J., Segall, M.D., Pickard, C.J., Hasnip, P.J., Probert, M.J., Refson, K., Payne, M.C., 2005. First principles methods using CASTEP. Zeitschrift Fur Kristallographie 220, 567-570. Cowan, C.E., Zachara, J.M., Resch, C.T., 1990. Solution ion effects on the surface exchange of selenite on calcite. Geochimica et Cosmochimica Acta 54, 2223-2234.

David, F., Vokhmin, V., lonova, G., 2001. Water characteristics depend on the ionic environment. Thermodynamics and modelisation of the aquo ions. Journal of Molecular Liquids 90, 45-62.

Demichelis, R., Raiteri, P., Gale, J.D., Quigley, D., Gebauer, D., 2011. Stable prenucleation mineral clusters are liquid-like ionic polymers. Nature Communications $\mathbf{2}$.

Elzinga, E.J., Rouff, A.A., Reeder, R.J., 2006. The long-term fate of $\mathrm{Cu}^{2+}, \mathrm{Zn}^{2+}$, and $\mathrm{Pb}^{2+}$ adsorption complexes at the calcite surface: An X-ray absorption spectroscopy study. Geochimica et Cosmochimica Acta 70, 2715-2725.

Fenter, P., Sturchio, N.C., 2012. Calcite (104)-water interface structure, revisited. Geochimica et Cosmochimica Acta 97, 58-69.

Fenter, P., Kerisit, S., Raiteri, P., Gale, J. D., 2013. Is the Calcite-Water Interface Understood? Direct Comparison of Molecular Dynamics Simulations with Specular X-ray Reflectivity Data. Journal of Physical Chemistry C 117, 5028-5042.

Fernández-Martínez, A., Charlet, L., 2009. Selenium environmental cycling and bioavailability: a structural chemist point of view. Reviews in Environmental Science and Biotechnology 8, 81-110. Gale, J.D., Rohl, A.L., 2003. The General Utility Lattice Program (GULP). Molecular Simulation 29, 291-341. Gale, J.D., Rohl, A.L., 2007. An efficient technique for the prediction of solvent-dependent morphology: The COSMIC method. Molecular Simulation 33, 1237-1246.

Glynn, P.D., 2000. Solid-solution solubilities and thermodynamics: Sulfates, carbonates, and halides, in: Alpers, C.N., Jambor, J.L., Nordstrom, D.K. (Eds.), Sulfate Minerals: Crystallography, Geochemistry, and Environmental Significance. Mineralogical Society of America, pp. 480-511. Heberling, F., Denecke, M.A., Bosbach, D., 2008. Neptunium(V) Coprecipitation with Calcite. Environmental Science \& Technology 42, 471-476. Heberling, F., Trainor, T.P., Lützenkirchen, J., Eng, P., Denecke, M.A., Bosbach, D., 2011. Structure and reactivity of the calcite-water interface. Journal of Colloid and Interface Science 354, 843-857. Henderson, L.M., Kracek, F.C., Parsons, C.L., Moore, R.B., Lind, S.C., Schaefer, O.C., Niermann, J.L., Scholl, C.E., Strong, R.K., Mc Coy, H.N., Ebler, E., van Rhyn, A.J., Doerner, H.A., Hoskins, W.M., Germann, F.E.E., 
1208

1209

1210

1211

1212

1213

1214

1215

1216

1217

1218

1219

1220

1221

1222

1223

1224

1225

1226

1227

1228

1229

1230

1231

1232

1233

1234

1235

1236

1237

1238

1239

1240

1241

1242

1243

1244

1245

1246

1247

1248

1249

1250

1251

1252

1253

1254

1255

1256
1928. Die fraktionierte Fällung von Barium- und Radiumchromaten. Fresenius Journal of Analytical Chemistry 74, 255-259.

Hummel, W., Berner, U., Curti, E., Pearson, F.J., Thoenen, T., 2002. Nagra/PSI chemical thermodynamic data base 01/01. Radiochimica Acta 90, 805-813.

Janecek, J., Netz, R.R., Flörsheimer, M., Klenze, R., Schimmelpfennig, B., Polly, R., 2013. A joint theoretical and experimental study of the solvated corundum (001) surface. I: Monte Carlo simulations and density functional theory calculations.

Jorg, G., Buhnemann, R., Hollas, S., Kivel, N., Kossert, K., Van Winckel, S., Gostomski, C.L.V., 2010. Preparation of radiochemically pure Se-79 and highly precise determination of its half-life. Applied Radiation and Isotopes 68, 2339-2351.

Kresse, G., Furthmuller, J., 1996a. Efficiency of ab-initio total energy calculations for metals and semiconductors using a plane-wave basis set. Computational Materials Science 6, 15-50.

Kresse, G., Furthmuller, J., 1996b. Efficient iterative schemes for ab initio total-energy calculations using a plane-wave basis set. Physical Review B 54, 11169-11186.

Kresse, G., Hafner, J., 1993a. Ab-Initio Molecular-Dynamics for Open-Shell Transition-Metals. Physical Review B 48, 13115-13118.

Kresse, G., Hafner, J., 1993b. Ab-Initio Molecular-Dynamics for Liquid-Metals. Physical Review B 47, 558-

561.

Kresse, G., Hafner, J., 1994. Ab-Initio Molecular-Dynamics Simulation of the Liquid-Metal AmorphousSemiconductor Transition in Germanium. Physical Review B 49, 14251-14269.

Kresse, G., Joubert, D., 1999. From ultrasoft pseudopotentials to the projector augmented-wave method. Physical Review B 59, 1758-1775.

Marcus, Y., 1991. Thermodynamics of Solvation of Ions .5. Gibbs Free-Energy of Hydration at $298.15 \mathrm{~K}$. Journal of the Chemical Society-Faraday Transactions 87, 2995-2999.

Masscheleyn, P.H., Delaune, R.D., Patrick, W.H., 1990. Transformations of selenium as affected by sediment oxidation-reduction potential and pH. Environmental Science \& Technology 24, 91-96. Monkhorst, H.J., Pack, J.D., 1976. Special points for Brillouin-zone integrations. Physical Review B 13, 5188-5192.

Montes-Hernandez, G., Sarret, G., Hellmann, R., Menguy, N., Testemale, D., Charlet, L., Renard, F., 2011. Nanostructured calcite precipitated under hydrothermal conditions in the presence of organic and inorganic selenium. Chemical Geology 290, 109-120.

Nielsen, A.E., Toft, J.M., 1984. Electrolyte Crystal Growth Kinetics. Journal of Crystal Growth 67, 278-288. Ogino, T., Suzuki, T., Sawada, K., 1987. The Formation and Transformation Mechanism of Calcium-

Carbonate in Water. Geochimica et Cosmochimica Acta 51, 2757-2767.

Olin, A., Noläng, B., Osadchii, E., Öhman, L.-O., Rosen, E., 2005. Chemical Thermodynamics of Selenium. OECD Nuclear Energy Agency (NEA).

Ondraf/Niras, 2001. Technical Overview of the SAFIR 2 Report, Safety Assessment and Feasibility Interim Report 2.

Parkhurst, D.L., Appelo, C.A.J., 1999. User's guide to PhreeqC (Version 2), Water-Ressources

Investigations Report. US Geological Survey, Denver, p. 326.

Perdew, J.P., Burke, K., Ernzerhof, M., 1996. Generalized gradient approximation made simple. Physical

Review Letters 77, 3865-3868.

Prieto, M., 2009. Thermodynamics of Solid Solution - Aqueous Solution Systems. Reviews in Mineralogy and Geochemistry 70, 47 - 85.

Raiteri, P., Gale, J.D., Quigley, D., Rodger, P.M., 2010. Derivation of an Accurate Force-Field for Simulating the Growth of Calcium Carbonate from Aqueous Solution: A New Model for the Calcite-Water Interface. Journal of Physical Chemistry C 114, 5997-6010.

Ravel, B., Newville, M., 2005. ATHENA, ARTEMIS, HEPHAESTUS: data analysis for X-ray absorption spectroscopy using IFEFFIT. Journal of Synchrotron Radiation 12, 537-541. 
Reeder, R.J., Nugent, M., Lamble, G.M., Tait, C.D., Morris, D.E., 2000. Uranyl incorporation into calcite and aragonite: XAFS and luminescence studies. Environmental Science \& Technology 34, 638-644. and its effect on crystal growth: An atomic force microscopy study. Chemical Geology 340, 151-161. Rothe, J., Butorin, S., Dardenne, K., Denecke, M.A., Kienzler, B., Loble, M., Metz, V., Seibert, A., Steppert, M., Vitova, T., Walther, C., Geckeis, H., 2012. The INE-Beamline for actinide science at ANKA. Review of Scientific Instruments 83.

Rouff, A.A., Elzinga, E.J., Reeder, R.J., Fisher, N.S., 2005. The influence of pH on the kinetics, reversibility and mechanisms of $\mathrm{Pb}$ (II) sorption at the calcite-water interface. Geochimica et Cosmochimica Acta 69, 5173-5186.

Polarized EXAFS evidence for the adsorption of Co on the edges of hectorite particles. Journal of Colloid and Interface Science 215, 140-158.

Shtukenberg, A.G., Punin, Y.O., Azimov, P., 2006a. Crystallization kinetics in binary solid solution-aqueous solution systems. American Journal of Science 306, 553-574.

Sluiter, M.H.F., Kawazoe, Y., 2002. Prediction of the mixing enthalpy of alloys. Europhysics Letters 57, 526-532

Stack, A.G., Grantham, M.C., 2010. Growth Rate of Calcite Steps As a Function of Aqueous Calcium-toCarbonate Ratio: Independent Attachment and Detachment of Calcium and Carbonate Ions. Crystal Growth \& Design 10, 1409-1413.

Stipp, S.L., Hochella, J., Michael F., 1991. Structure and bonding environments at the calcite surface as observed with X-ray photoelectron spectroscopy (XPS) and low energy electron diffraction (LEED). Geochimica et Cosmochimica Acta 55, 1723-1736.

Tesoriero, A.J., Pankow, J.F., 1996. Solid solution partitioning of $\mathrm{Sr}^{2+}, \mathrm{Ba}^{2+}$, and $\mathrm{Cd}^{2+}$ to calcite. Geochimica et Cosmochimica Acta 60, 1053-1063.

Tkatchenko, A., Scheffler, M., 2009. Accurate Molecular Van Der Waals Interactions from Ground-State Electron Density and Free-Atom Reference Data. Physical Review Letters 102, 073005.

Valiev, M., Bylaska, E.J., Govind, N., Kowalski, K., Straatsma, T.P., Van Dam, H.J.J., Wang, D., Nieplocha, J., Apra, E., Windus, T.L., de Jong, W., 2010. NWChem: A comprehensive and scalable open-source solution for large scale molecular simulations. Computer Physics Communications 181, 1477-1489.

Vinograd, V.L.,Brandt, F., Rozov, K., Klinkenberg, M., Refson, K.,Winkler, B.,Bosbach, D., (accepted). Solidaqueous equilibrium in the $\mathrm{BaSO}_{4}-\mathrm{RaSO}_{4}-\mathrm{H}_{2} \mathrm{O}$ system: first-principles calculations and a thermodynamic assessment. Geochimica et Cosmochimica Acta XXX, XXXX-XXXX.

Wang, J., Roman-Perez, G., Soler, J.M., Artacho, E., Fernandez-Serra, M.V., 2011. Density, structure, and dynamics of water: The effect of van der Waals interactions. The Journal of Chemical Physics 134, 24516. Wang, X.K., Liu, X.P., 2005. Sorption and desorption of radioselenium on calcareous soil and its solid components studied by batch and column experiments. Applied Radiation and Isotopes 62, 1-9. Wang, Y.F., Xu, H.F., 2001. Prediction of trace metal partitioning between minerals and aqueous solutions: A linear free energy correlation approach. Geochimica et Cosmochimica Acta 65, 1529-1543. Watson, E.B., 2004. A conceptual model for near-surface kinetic controls on the trace-element and stable isotope composition of abiogenic calcite crystals. Geochimica et Cosmochimica Acta 68, 1473-1488. Wicke, H., Meleshyn, A., 2010. Microhydration of the Selenite Dianion: A Theoretical Study of Structures, Hydration Energies, and Electronic Stabilities of $\mathrm{SeO}_{3}{ }^{2-}\left(\mathrm{H}_{2} \mathrm{O}\right)(\mathrm{n})(\mathrm{n}=0-6,9)$ Clusters. Journal of Physical Chemistry A 114, 8948-8960.

Wickleder, M.S., 2002. Sodium selenite, $\mathrm{Na}_{2} \mathrm{SeO}_{3}$. Acta Crystallographica Section E-Structure Reports Online 58, I103-I104.

Wildner, M., Giester, G., 2007. Crystal structures of $\mathrm{SrSeO}_{3}$ and $\mathrm{CaSeO}_{3}$ and their respective relationships with molybdomenite- and monazite-type compounds - an example for stereochemical equivalence of 
$1305 \mathrm{ESeO}_{3}$ groups ( $\mathrm{E}=$ lone electron pair) with tetrahedral $\mathrm{TO}_{4}$ groups. Neues Jahrbuch Fur Mineralogie1306 Abhandlungen 184, 29-37.

1307 Wu, Z.G., Cohen, R.E., 2006. More accurate generalized gradient approximation for solids. Physical 1308 Review $B 73$.

1309 Zhao, Y., Truhlar, D.G., 2008. The M06 suite of density functionals for main group thermochemistry, 1310 thermochemical kinetics, noncovalent interactions, excited states, and transition elements: two new 1311 functionals and systematic testing of four M06-class functionals and 12 other functionals. Theoretical 1312 Chemistry Accounts 120, 215.

1313 Zhong, S.J., Mucci, A., 1995. Partitioning of Rare-Earth Elements (REEs) between Calcite and Seawater 1314 Solutions at 25-Degrees-C and $1 \mathrm{Atm}$, and High Dissolved REE Concentrations. Geochimica et 1315 Cosmochimica Acta 59, 443-453.

1316 
1318

1319

1320

1321

1322

1323

1324

1325

1326

1327

1328

1329

1330

1331

1332

1333

1334

1335

1336

1337

1338

1339

1340

1341

1342

1343

1344

1345

1346

1347

1348

1349

1350

1351

1352

1353

1354

1355

1356

\section{Figure Captions}

Figure 1: The relation between the host phase calcite, the reference phase $\mathrm{CaSeO}_{3}$ (monocl.) and the virtual $\mathrm{CaSeO}_{3}$ endmember in terms of excess free energy. Indicated is the hypothetical ideal (linear dashed) behavior of the virtual solid solution, as opposed to behavior of the real solid solution (solid curve), which is equal to the virtual solid solution at low mole fractions of $\mathrm{CaSeO}_{3}$ and then follows an arbitrary trend.

Figure 2: EXAFS data. Figure 2a) shows the $\mathrm{k}^{2}$-weighted EXAFS data (circles) and the corresponding model curves (lines) from isotropic (black, labeled: iso) and the polarization dependent measurements (blue, green, red, labeled: bpb, bpk, bpa (for explanation please refer to section 3.2)). Fourier transformed EXAFS data (circles) and modeling results (lines) are shown in Figures b) and c). Figure $2 b$ ) shows the Fourier transform magnitude and imaginary part of the isotropic data, while Figure 2c) shows the Fourier transform magnitudes of the polarization dependent data. For reasons of clarity the imaginary parts are not depicted.

Figure 3: Effective coordination numbers $\left(N_{\text {eff }}\right)$ for the three different orientations $b p a, b p b$, and $b p k$, resulting from the polarization dependent EXAFS experiment (exp) compared to effective coordination numbers according to a simple structural model adjusted to fit the measurements using equation (23) (model) and according to the structure obtained from WC-USP calculations (theory). Error bars plotted for the experimental $\mathrm{N}_{\text {eff }}$ values are standard deviation calculated by the ARTEMIS software.

Figure 4: Ball and stick representation of the proposed best-fit structure (Ca: green, O: red, Se: yellow). Indicated are the orientation of the calcite (104) plane and the directions of the polarization vectors during the polarization dependent measurements. The selenite ion substitutes a carbonate ion in the calcite structure, the selenium atom is located $0.65 \AA$ above the carbon position in calcite, the selenite oxygen atoms are $0.1 \AA$ below the plane of the original carbonate ion and $1.51 \AA$ away from the central axis to yield a trigonal pyramid, as expected for selenite. The calcite environment reacts mainly by upwards and lateral displacement of the calcium atoms, which are located above the selenium atom. ("up" implies the positive direction along the $c$-axis)

Figure 5: Solid composition, $\mathrm{X}\left(\mathrm{CaSeO}_{3}\right) / \mathrm{X}$ (calcite), of selenite doped calcite as a function of the composition of the growth (equilibrium) solution, $\mathrm{c}\left(\mathrm{SeO}_{3}{ }^{2-}\right) / \mathrm{c}\left(\mathrm{CO}_{3}{ }^{2-}\right)$. Over a large range of solid compositions a linear trend is observed, which indicates a constant partition coefficient, consistent with ideal or Henry's law mixing behavior. Results from MFR experiments (red diamonds) are compared to results from adsorption experiments (orange circles). Adsorption data at the highest Se concentration is taken from Cheng et al. (Cheng et al., 1997), data at intermediate concentrations is adopted from Cowan et al. (Cowan et al., 1990), adsorption data at the lowest Se concentration is from this study. Error bars show uncertainties estimated for a single measurement based on error propagation calculations.

Figure 6: Schematic representation of the entrapment concept. Left, coprecipitation scenario: 1) The composition of the solid surface $\left(\mathrm{SeO}_{3}{ }^{2-} / \mathrm{CO}_{3}{ }^{2-}\right.$ ratio) "equilibrates" with the aqueous solution according to $\Delta \mathrm{G}_{\text {surface }}^{\mathrm{E}}=2 \pm 2 \mathrm{~kJ} / \mathrm{mol}$, meaning the most highly supersaturated surface solid solution forms. 2) Upon growth, the surface solid solution is covered by subsequent crystal layers while keeping its composition. 
The final bulk solid solution, characterized by the thermodynamic properties of the bulk endmember,

$1358 \mathrm{CaSeO}_{3}$ bulk, is highly strained and out of equilibrium. 3) lons in the bulk cannot exchange with ions in 1359 solution except through the surface. Therefore, the surface solid solution may passivate the bulk solid solution against equilibration with aqueous solution. Indicated is the amount of free energy, $\Delta G_{\text {entrapment, }}$ required for the entrapment process, i.e. the transformation of the surface solid solution into a bulk solid solution of equal composition. Middle, calcite equilibrium conditions: 1) The solid surface equilibrates with the aqueous solution, a surface solid solution forms through a surface ion-exchange / recrystallization process. 2) As there is no driving force for entrapment, no bulk incorporation / recrystallization is expected. 3 ) If the bulk is pure calcite, no reaction is expected. If there is a nonequilibrium bulk solid solution underneath the surface the same passivation effect as for supersaturated conditions may apply. Right, growth inhibition scenario: 1) The solid surface equilibrates with the aqueous solution. Even though the aqueous solution is supersaturated with respect to pure calcite, the supersaturation is not sufficient to accomplish entrapment. Therefore solid solution growth is inhibited and only surface ion exchange occurs.

1371 Figure 7: $\mathrm{K}_{\mathrm{D}}$ values for selenite adsorption on calcite as a function of solution $\mathrm{pH}$, as derived from batch 1372 type adsorption experiments in this study. Error bars show uncertainties estimated for a single measurement based on error propagation calculations.

Figure 8: Aragonite $\rightarrow$ calcite recrystallization experiments. In the selenite free system (blue diamonds) the calcite fraction increases during the run of the experiment due to recrystallization of aragonite to calcite. In the selenite containing system (red squares) the formation of calcite is inhibited.

Figure 9: MFR growth rates in the presence (red squares) and absence (violet triangles) of Se(IV), and AFM growth rates (blue diamonds, (Renard et al., 2013)) plotted as a function of supersaturation with respect to the bulk solid solution. For the conversion of microscopic AFM growth rates $(\mathrm{nm} / \mathrm{s})$ to macroscopic growth rates $\left(\mathrm{nmol} /\left(\mathrm{m}^{2} \mathrm{~s}\right)\right)$ a step density of $0.4 \mu \mathrm{m}^{-1}$ has been assumed. Error bars show uncertainties estimated for a single measurement based on error propagation calculations. 
Table 1: Reaction conditions during MFR experiments. Listed are the input concentration of selenium, $\mathrm{c}_{0}(\mathrm{Se})$, the reactive calcite surface inside the MFR, $\mathrm{A}$ (calcite), the average $\mathrm{pH}$ after the MFR, $\mathrm{pH}_{\text {out }}$, the average supersaturation after the MFR, which is meant to represent steady state conditions, $\mathrm{SI}_{\text {out, }}$, the pumping rate, $F$, the solid solution growth rate, $R_{C a}$, and the partition coefficient, $D$.

\begin{tabular}{|c|c|c|c|c|c|c|c|}
\hline label & $\begin{array}{l}\mathrm{c}_{0}(\mathrm{Se}) \\
\mathrm{mol} / \mathrm{L}\end{array}$ & $\begin{array}{c}\text { A(calcite) } \\
\mathrm{m}^{2}\end{array}$ & $\mathrm{pH}_{\text {out }}$ & $\mathrm{SI}_{\text {out }}$ & $\begin{array}{c}F \\
\mathrm{~mL} / \mathrm{min}\end{array}$ & $\begin{array}{c}R_{\mathrm{ca}} \\
10^{-9} \mathrm{~mol} /\left(\mathrm{m}^{2} \mathrm{~s}\right)\end{array}$ & D \\
\hline $\begin{array}{l}\text { MFR-Se } 1 \\
(\Delta \mathrm{Ca})\end{array}$ & $1.7 \cdot 10^{-13}$ & $\begin{array}{r}0.082 \\
\pm 0.007\end{array}$ & $\begin{array}{r}7.73 \\
\pm 0.08\end{array}$ & $\begin{array}{r}0.7 \\
\pm 0.1\end{array}$ & $\begin{array}{r}0.29 \\
\pm 0.02\end{array}$ & $16 \pm 12$ & $\begin{array}{r}0.05 \\
\pm 0.04\end{array}$ \\
\hline $\begin{array}{l}\text { MFR-Se } 2 \\
(\Delta \mathrm{Ca})\end{array}$ & $2.5 \cdot 10^{-10}$ & $\begin{array}{r}0.082 \\
\pm 0.007\end{array}$ & $\begin{array}{r}7.72 \\
\pm 0.09\end{array}$ & $\begin{array}{r}0.7 \\
\pm 0.1\end{array}$ & $\begin{array}{r}0.286 \\
\pm 0.005\end{array}$ & $10 \pm 6$ & $\begin{array}{r}0.07 \\
+0.05\end{array}$ \\
\hline $\begin{array}{l}\text { MFR-Se } 3 \\
(\Delta \mathrm{Ca})\end{array}$ & $2.5 \cdot 10^{-7}$ & $\begin{array}{r}0.15 \\
\pm 0.01\end{array}$ & $\begin{array}{r}7.47 \\
\pm 0.05\end{array}$ & $\begin{array}{r}0.43 \\
\pm 0.06\end{array}$ & $\begin{array}{r}0.270 \\
\pm 0.007\end{array}$ & $6 \pm 4$ & $\begin{array}{r}0.002 \\
\pm 0.001\end{array}$ \\
\hline $\begin{array}{l}\text { MFR-Se } 4 \\
(\Delta \mathrm{pH})\end{array}$ & $6.7 \cdot 10^{-6}$ & $\begin{array}{r}0.15 \\
\pm 0.01\end{array}$ & $\begin{array}{r}7.56 \\
\pm 0.05\end{array}$ & $\begin{array}{r}0.50 \\
\pm 0.06\end{array}$ & $\begin{array}{r}0.267 \\
\pm 0.003\end{array}$ & $3 \pm 2$ & $\begin{array}{r}0.02 \\
\pm 0.01\end{array}$ \\
\hline $\begin{array}{l}\text { MFR-Se } 5 \\
(\Delta \mathrm{pH})\end{array}$ & $1.7 \cdot 10^{-5}$ & $\begin{array}{r}0.15 \\
\pm 0.01\end{array}$ & $\begin{array}{r}7.43 \pm \\
0.04\end{array}$ & $\begin{array}{r}0.39 \\
\pm 0.05\end{array}$ & $\begin{array}{r}0.288 \\
\pm 0.002\end{array}$ & $7 \pm 5$ & $\begin{array}{r}0.02 \\
\pm 0.01\end{array}$ \\
\hline $\begin{array}{l}\text { MFR-Se } 6 \\
(\Delta \mathrm{pH})\end{array}$ & $3.3 \cdot 10^{-5}$ & $\begin{array}{r}0.15 \\
\pm 0.01\end{array}$ & $\begin{array}{r}7.60 \pm \\
0.04\end{array}$ & $\begin{array}{r}0.59 \\
\pm 0.05\end{array}$ & $\begin{array}{r}0.297 \\
\pm 0.001\end{array}$ & $7 \pm 5$ & $\begin{array}{r}0.02 \\
\pm 0.01\end{array}$ \\
\hline $\begin{array}{l}\text { MFR-Se } 7 \\
(\Delta \mathrm{Ca})\end{array}$ & $2.5 \cdot 10^{-4}$ & $\begin{array}{r}0.082 \\
\pm 0.007\end{array}$ & $\begin{array}{r}8.0 \\
\pm 0.1\end{array}$ & $\begin{array}{r}0.9 \\
\pm 0.2\end{array}$ & $\begin{array}{r}0.277 \\
\pm 0.001\end{array}$ & $7 \pm 4$ & $\begin{array}{r}0.01 \\
\pm 0.01\end{array}$ \\
\hline $\begin{array}{l}\text { MFR-Se EXAFS } \\
(\Delta \mathrm{Ca})\end{array}$ & $1.1 \cdot 10^{-4}$ & $\begin{array}{r}0.20 \\
\pm 0.02\end{array}$ & $\begin{array}{r}10.33 \\
\pm 0.02\end{array}$ & $\begin{array}{r}1.0 \\
\pm 0.1\end{array}$ & $\begin{array}{r}0.59 \\
\pm 0.01\end{array}$ & $12 \pm 1$ & \\
\hline MFR-Cc1 & 0 & $\begin{array}{r}0.082 \\
\pm 0.006\end{array}$ & $\begin{array}{r}7.31 \\
\pm 0.04\end{array}$ & $\begin{array}{r}0.25 \\
\pm 0.05\end{array}$ & $\begin{array}{r}0.57 \\
\pm 0.02\end{array}$ & $17 \pm 14$ & \\
\hline MFR-Cc2 & 0 & $\begin{array}{r}0.082 \\
\pm 0.006\end{array}$ & $\begin{array}{r}7.36 \\
\pm 0.12\end{array}$ & $\begin{array}{r}0.28 \\
\pm 0.1\end{array}$ & $\begin{array}{r}0.28 \\
\pm 0.01\end{array}$ & $16 \pm 3$ & \\
\hline
\end{tabular}

1390

1391

Table 2: Results from EXAFS data modeling: Bond distances, $R$, Debye Waller factors, $\sigma^{2}$, coordination number obtained from modeling the isotropic data, $\mathrm{N}_{\text {iso, }}$ and effective coordination numbers obtained from the polarization dependent data, $\mathrm{N}_{\text {eff. }}$. DFT based bond distances calculated using the WC-USP and PBE-PAW methods (see text for explanation) are listed for comparison.

\begin{tabular}{|c|c|c|c|c|c|c|c|c|c|c|}
\hline & \multicolumn{3}{|c|}{ isotropic / powder } & \multicolumn{5}{|c|}{ polarization dependent / single crystal } & WC-USP & PBE-PAW \\
\hline shell & $\mathrm{R}[\AA \AA]$ & $\sigma^{2}\left[\AA^{2}\right]$ & $\mathrm{N}_{\text {iso }}$ & $\mathrm{R}[\AA ̊]$ & $\sigma^{2}\left[\AA^{2}\right]$ & $\mathrm{N}_{\text {eff }}(\mathrm{bpa})$ & $\mathrm{N}_{\text {eff }}(\mathrm{bpb})$ & $\mathrm{N}_{\text {eff }}(\mathrm{bpk})$ & $\mathrm{R}[\AA ̊]$ & $\mathrm{R}[\AA \AA]$ \\
\hline $\begin{array}{l}\mathrm{O}- \\
\mathrm{SeO}_{3}\end{array}$ & $\begin{array}{r}1.68 \\
\pm 0.01\end{array}$ & $\begin{array}{r}0.001 \\
\pm 0.001\end{array}$ & $\begin{array}{r}3.0 \\
\pm 0.1\end{array}$ & $\begin{array}{r}1.68 \\
\pm 0.01\end{array}$ & $\begin{array}{r}0.001 \\
\pm 0.001\end{array}$ & $3.8 \pm 0.2$ & $2.9 \pm 0.2$ & $3.1 \pm 0.4$ & 1.71 & 1.73 \\
\hline $\begin{array}{l}\mathrm{O}- \\
\mathrm{CO}_{3}\end{array}$ & $\begin{array}{r}2.88 \\
\pm 0.02\end{array}$ & $\begin{array}{r}0.013 \\
\pm 0.006\end{array}$ & $\begin{array}{r}3.1 \\
\pm 0.7\end{array}$ & $\begin{array}{r}2.88 \\
\pm 0.02\end{array}$ & $\begin{array}{r}0.008 \\
\pm 0.003\end{array}$ & $1.9 \pm 0.6$ & $3.2 \pm 0.6$ & $3.1 \pm 1.1$ & 2.87 & 2.93 \\
\hline Ca1 & 3.26 & 0.010 & 2.7 & 3.26 & 0.012 & $3.6 \pm 0.8$ & $2.7 \pm 0.7$ & $3.3 \pm 1.4$ & 3.27 & 3.26 \\
\hline
\end{tabular}




\begin{tabular}{|l|r|r|r|r|r|r|r|r|r|r|}
\hline & \pm 0.02 & \pm 0.003 & \pm 0.7 & \pm 0.02 & \pm 0.002 & & & & & \\
\hline Ca2 & 3.50 & 0.009 & 2.6 & 3.46 & 0.008 & $3.0 \pm 0.7$ & $2.8 \pm 0.6$ & $2.5 \pm 1.3$ & 3.52 & 3.59 \\
& \pm 0.03 & \pm 0.003 & \pm 0.8 & \pm 0.05 & \pm 0.002 & & & \\
\hline
\end{tabular}

1395 Uncertainties are standard deviations calculated by ARTEMIS.

1396 Table 3: Compilation of thermodynamic data used and obtained in this study

\begin{tabular}{|c|c|c|c|}
\hline Phase / Species & $\begin{array}{l}\Delta \mathrm{G}^{0} \\
(\mathrm{~kJ} / \mathrm{mol}, \text { at } 298.15 \mathrm{~K})\end{array}$ & $\log _{10} K_{S P}$ & reference \\
\hline $\mathrm{CaCO}_{3}$ (calcite) & -1129.08 & -8.48 & (Hummel et al., 2002) \\
\hline $\mathrm{CaSeO}_{3} \cdot \mathrm{H}_{2} \mathrm{O}$ & -1188.87 & -6.40 & (Olin et al., 2005) \\
\hline $\mathrm{BaCO}_{3}$ & -1134.4 & & (Hummel et al., 2002) \\
\hline $\mathrm{BaSeO}_{3}$ & -957.2 & & (Olin et al., 2005) \\
\hline $\mathrm{CaCO}_{3}$ (aragonite) & -1128.3 & -8.34 & (Hummel et al., 2002) \\
\hline $\mathrm{SrCO}_{3}$ & -1144.7 & & (Hummel et al., 2002) \\
\hline $\mathrm{SrSeO}_{3}$ & -962.2 & & (Olin et al., 2005) \\
\hline $\begin{array}{l}\mathrm{CaSeO}_{3} \text { (monoclinic, reference } \\
\text { phase) }\end{array}$ & $-955.5 \pm 4$ & $-7.06 \pm 0.7$ & this work \\
\hline $\mathrm{Ca}^{2+}{ }_{(\mathrm{aq})}$ & -552.81 & & (Olin et al., 2005) \\
\hline $\mathrm{CO}_{3}{ }^{2-}(\mathrm{aq})$ & -527.90 & & (Olin et al., 2005) \\
\hline $\mathrm{SeO}_{3}{ }^{2-}(\mathrm{aq})$ & -362.39 & & (Olin et al., 2005) \\
\hline $\mathrm{H}_{2} \mathrm{O}_{(l)}$ & -237.14 & & (Olin et al., 2005) \\
\hline $\mathrm{CaSeO}_{3 \text { bulk }}(\mathrm{WC}-\mathrm{USP})$ & -919 & & this work \\
\hline $\mathrm{CaSeO}_{3 \text { bulk }}(\mathrm{PBE}-\mathrm{PAW})$ & -907 & & this work \\
\hline $\mathrm{CaSeO}_{3 \text { bulk }}$ (PBE-USP) & -912 & & this work \\
\hline $\mathrm{CaSeO}_{3 \text { bulk }}$ (average) & $-912 \pm 10$ & $0.5 \pm 1.7$ & this work \\
\hline $\mathrm{CaSeO}_{3 \text { virtual }}$ (experiment) & $-953 \pm 6$ & $-6.7 \pm 1.0$ & this work \\
\hline
\end{tabular}

1398 Table 4: $\Delta G^{E}$ values and corresponding partition coefficients, $D$.

\begin{tabular}{|l|l|l|l|}
\hline structure & source & $\Delta \mathbf{G}^{\mathrm{E}}(\mathbf{k J} / \mathbf{m o l})$ & $\mathbf{D}$ \\
\hline bulk & average & $43 \pm 6$ & $10^{-9}( \pm 10 \mathrm{M})^{*}$ \\
\hline Calcite-vacuum interface & PBE-PAW & -15 & 15 \\
\hline Calcite-vacuum interface & WC-USP & -7 & 1 \\
\hline Calcite-vacuum interface & PBE-USP & -12 & 5 \\
\hline Calcite-vacuum interface & average & $-11 \pm 4$ & $7( \pm 10 \mathrm{M})^{*}$ \\
\hline Calcite-water interface (Se1) & PBE-PAW & 26 & $1.2 \cdot 10^{-6}$ \\
\hline Calcite-water interface (Se2) & PBE-PAW & 22 & $5.7 \cdot 10^{-6}$ \\
\hline Calcite-water interface (Se1) & PBE+D-USP & 23 & $3.7 \cdot 10^{-6}$ \\
\hline Calcite-water interface (Se2) & PBE+D-USP & 11 & $4.3 \cdot 10^{-4}$ \\
\hline Calcite-water interface (Se2) & average (Se2) & $16( \pm 10-18)$ & $5.0 \cdot 10^{-5}( \pm 2-4$ OM) \\
\hline Calcite-water interface & experimental & $2 \pm 2$ & $0.02 \pm 0.01$ \\
\hline
\end{tabular}

$\left.1399{ }^{*}\right) \pm x O M= \pm x$ order(s) of magnitude 


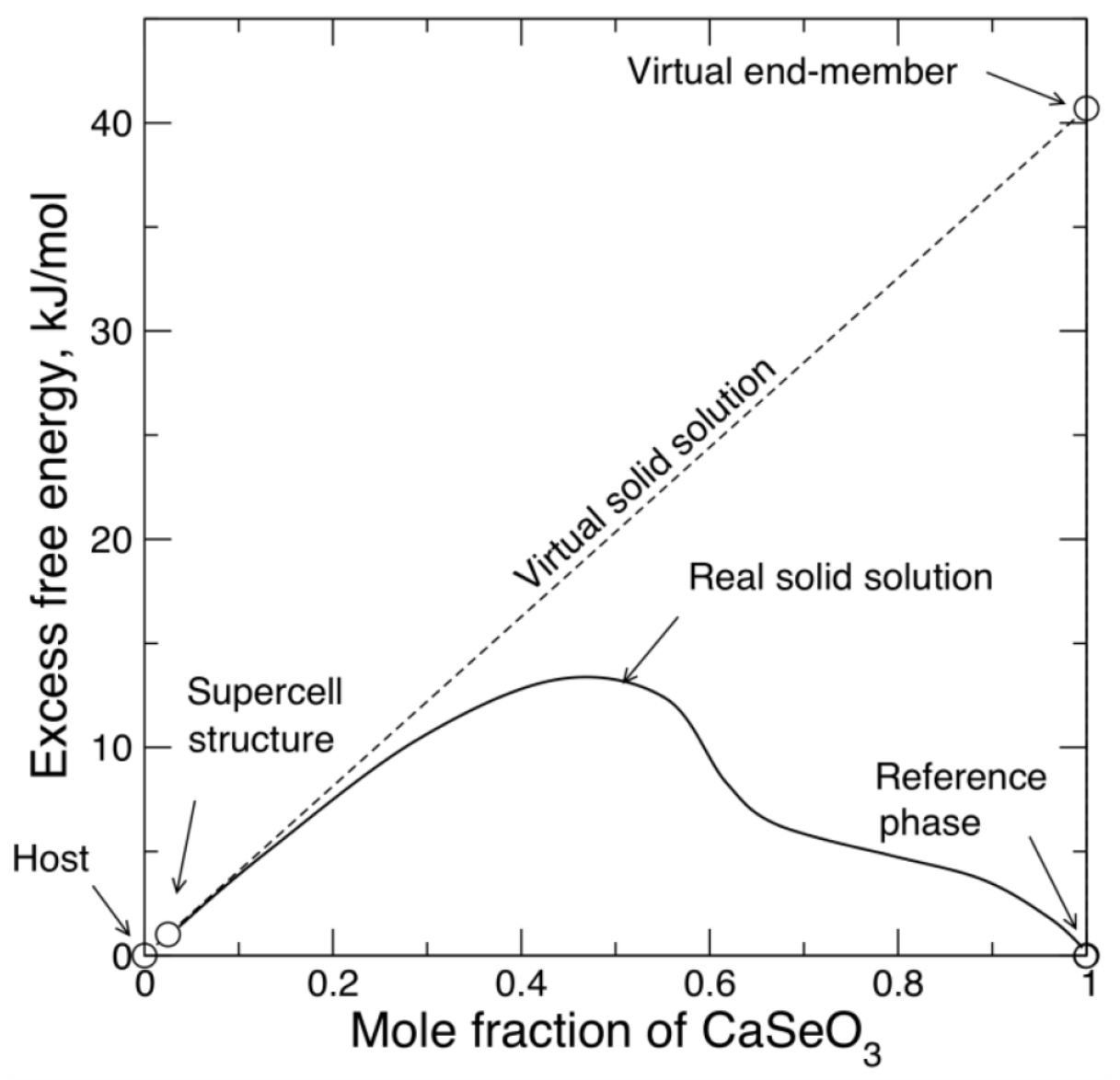

1403 Figure 1

1404
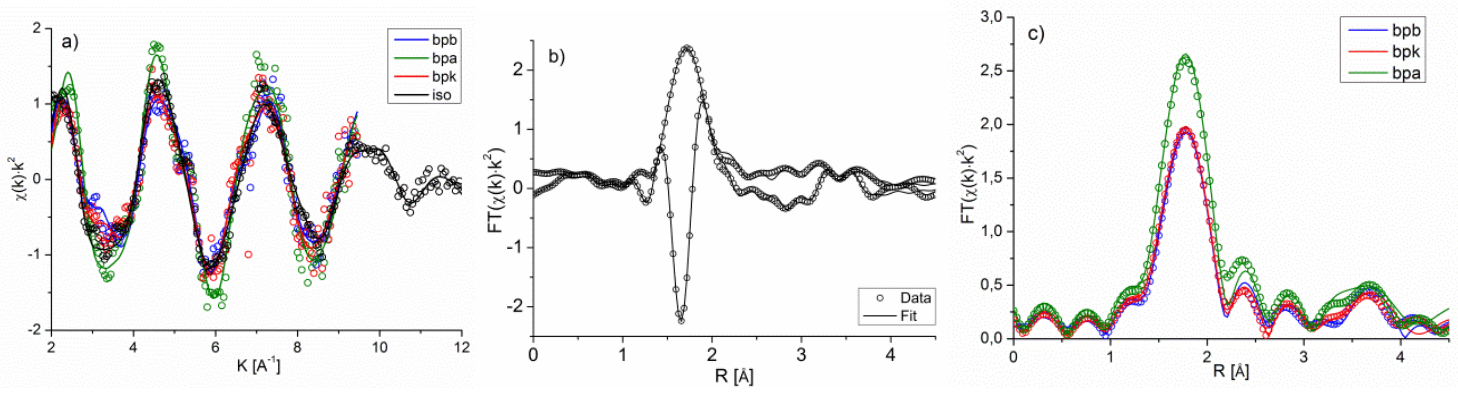

Figure 2 


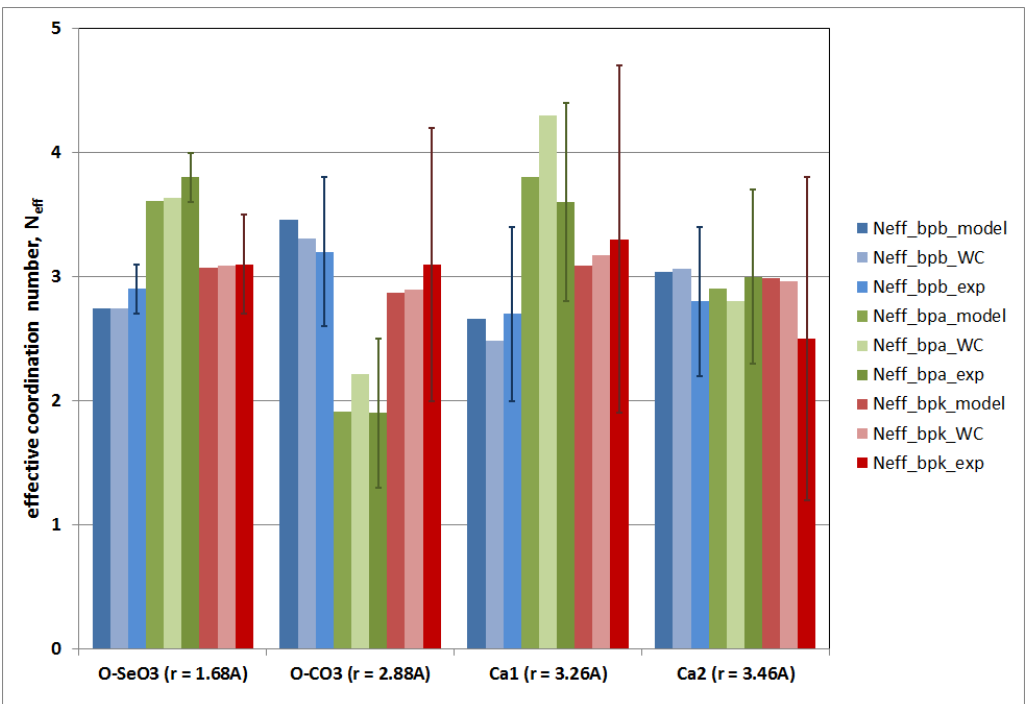

1408

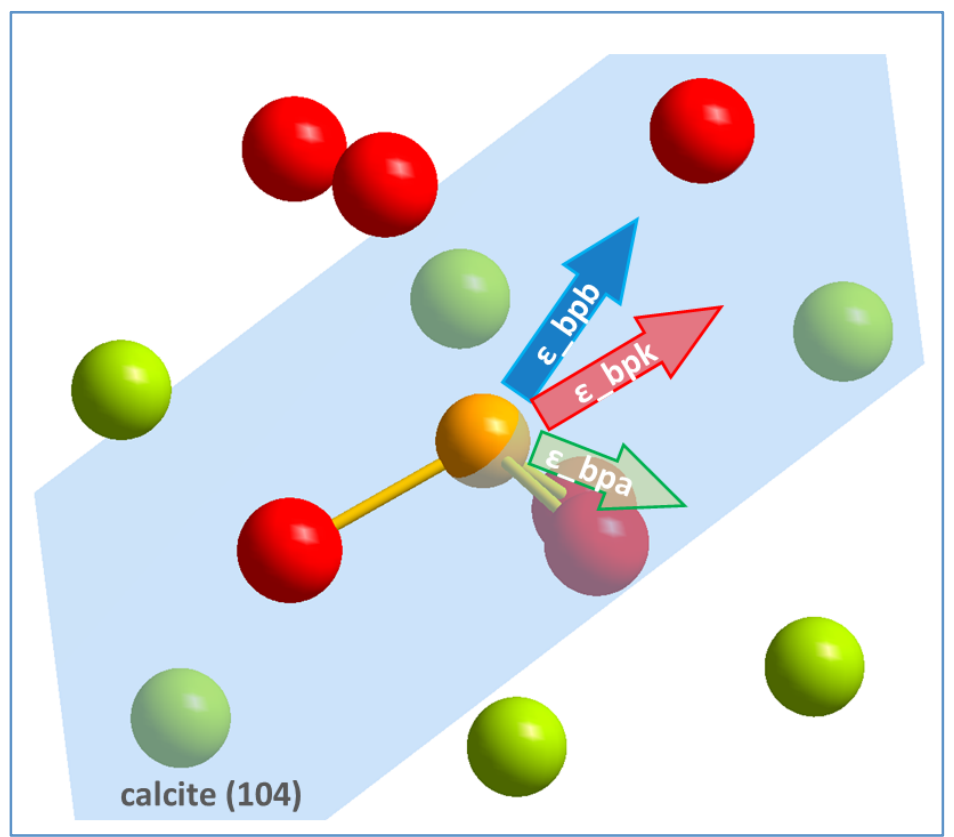

Figure 3

Figure 4 


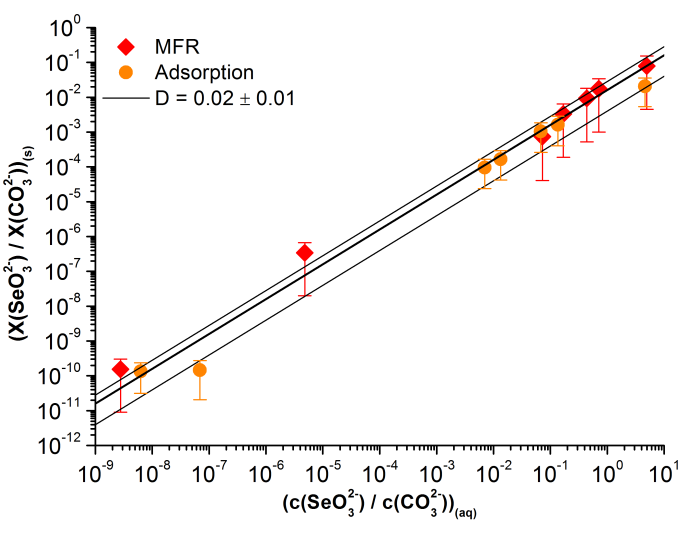

1411

1412
Figure 5
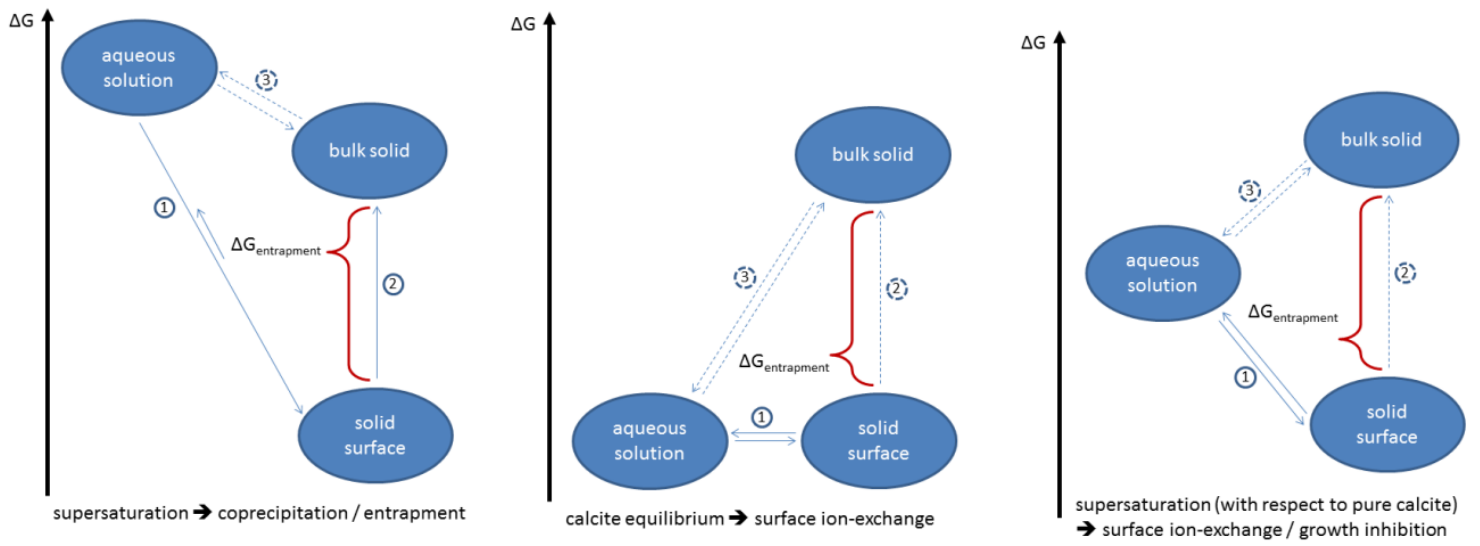

1413 Figure 6 


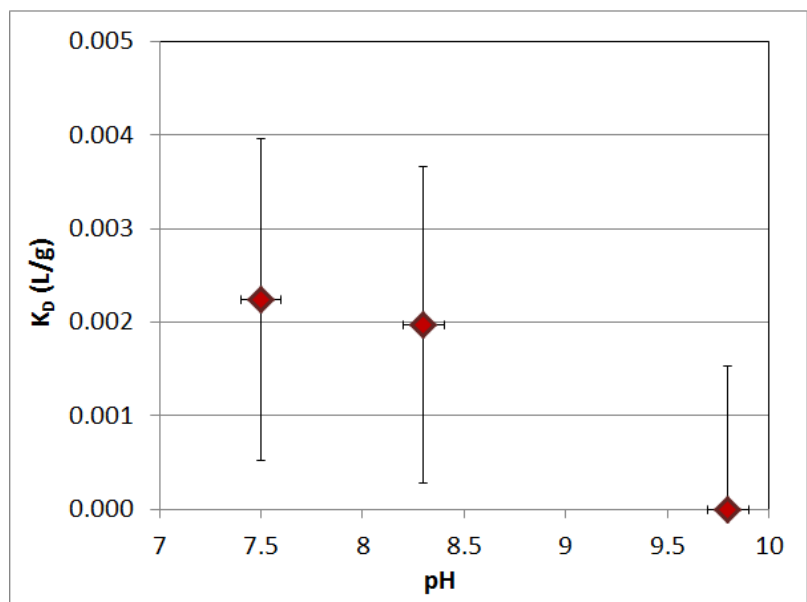

1417 Figure 7

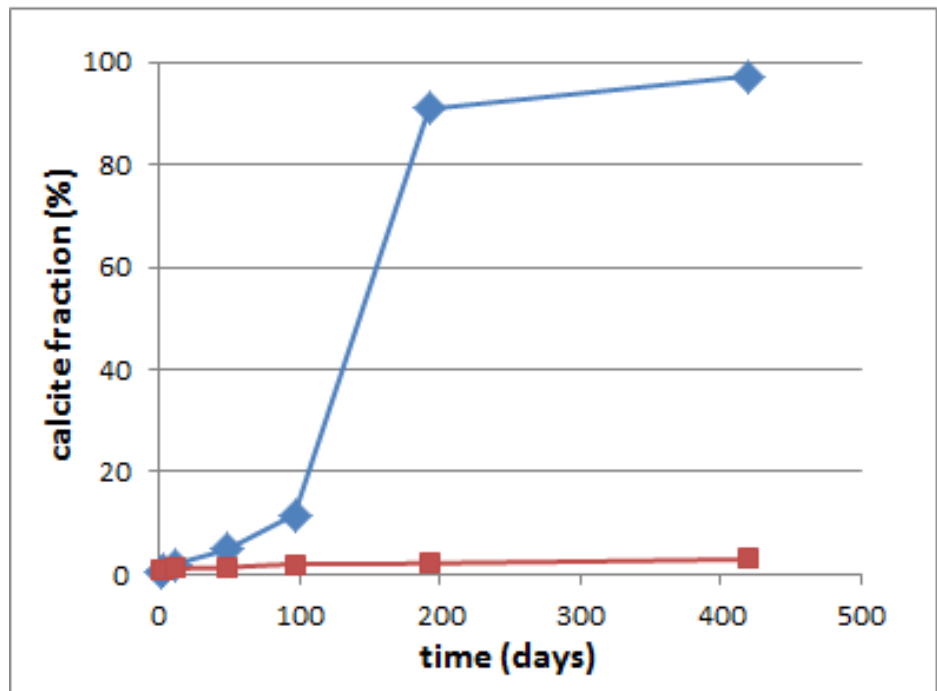

1418

Figure 8

1419 


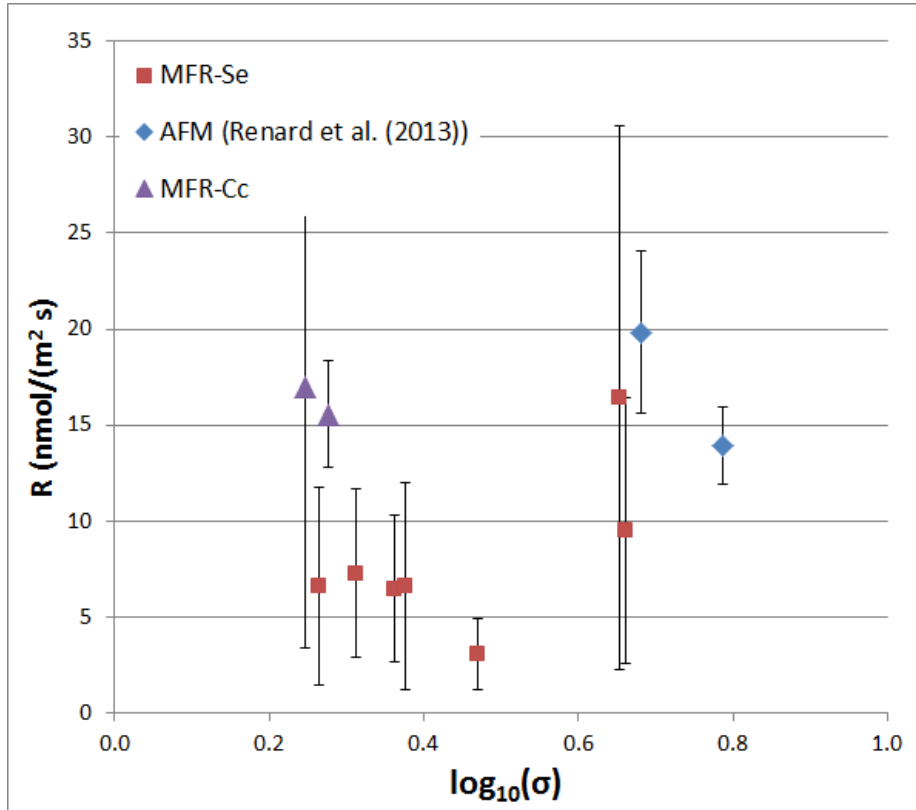

Figure 9 